\title{
Flow in gaming: literature synthesis and framework development
}

\section{Fiona Fui-Hoon Nah*}

Department of Business and Information Technology, Missouri University of Science and Technology, 101 Fulton Hall, Rolla, Missouri 65409, USA

E-mail: nahf@mst.edu

*Corresponding author

\section{Brenda Eschenbrenner}

Department of Accounting and Finance,

College of Business and Technology,

University of Nebraska at Kearney,

Kearney, Nebraska 68849, USA

E-mail: eschenbrenbl@unk.edu

\section{Qing Zeng and Venkata Rajasekhar Telaprolu}

Department of Business and Information Technology, Missouri University of Science and Technology, 101 Fulton Hall, Rolla, Missouri 65409, USA

E-mail: qzdg9@mst.edu

E-mail: vtfnd@mst.edu

\section{Sepandar Sepehr}

DeGroote School of Business, McMaster University,

Hamilton, Ontario, L8S 4M4, Canada

E-mail: sepehrs@mcmaster.ca

\begin{abstract}
Flow, a state of optimal experience where one is completely absorbed and immersed in an activity, is an important phenomenon for studying and designing games. In this article, we synthesise the literature on flow in gaming to discern existing research streams, and identify the antecedents, dimensions, and outcomes of flow which are then integrated into a framework. Based on the findings, we provide suggestions for game design elements that practitioners, such as game designers, may find useful for creating or inducing flow in gaming. We also discuss implications for research and practice as well as provide suggestions for future research.
\end{abstract}

Keywords: flow; gaming; framework; game design elements. 
Reference to this paper should be made as follows: Nah, F.F-H., Eschenbrenner, B., Zeng, Q., Telaprolu, V.R. and Sepehr, S. (2014) 'Flow in gaming: literature synthesis and framework development', Int. J. Information Systems and Management, Vol. 1, Nos. 1/2, pp.83-124.

Biographical notes: Fiona Fui-Hoon Nah is a Professor of Business and Information Technology at the Missouri University of Science and Technology, formerly the University of Missouri-Rolla. She received her $\mathrm{PhD}$ in Management Information Systems from the University of British Columbia. She holds an MS and BS (Honours) in Computer and Information Sciences from the National University of Singapore. Her research interests include human-computer interaction, virtual communities and virtual worlds, electronic commerce, mobile and ubiquitous commerce, enterprise resource planning, and applications of technology in education.

Brenda Eschenbrenner is an Assistant Professor at the University of Nebraska at Kearney. She received her PhD in Management Information Systems, with concentrations in accounting, human cognition, and information technology from the University of Nebraska-Lincoln. She also holds an MBA with concentrations in Management Information Systems and Finance, BS in Business Administration with emphasis in Accounting, and CPA (Inactive Registrant) certificate. The core of her research interests is in human-computer interaction where she focuses on emerging technologies, information systems user competency, and technology applications in education and training.

Qing Zeng is pursuing his MS in Information Science and Technology at the Missouri University of Science and Technology. He also holds an MS in Industrial and Management Systems Engineering at the University of Nebraska-Lincoln. His research interest is in human-computer interaction. He is working as a Research Assistant in the Laboratory for Information Technology Evaluation at the Missouri University of Science and Technology, and is pursuing his Master thesis in human-computer interaction.

Venkata Rajasekhar Telaprolu is pursuing his MS in Information Science and Technology at the Missouri University of Science and Technology. His research interest is in human-computer interaction, with a focus in the application of flow theory in human-computer interaction. He had worked at TATA Consultancy Services, India Ltd. for more than three years studying various underlying business and technology concepts in the banking industry.

Sepandar Sepehr is a $\mathrm{PhD}$ candidate of Information Systems at the DeGroote School of Business at McMaster University. He holds an MS in Computer Science from McMaster University and BS in Computer Software Engineering from University of Tehran, Iran. His main research area falls under the discipline of human-computer interaction. His research interests include adoption of, continuing use of, engagement in, and addiction to information systems, in particular video games used for improving learning and working experience and producing positive health outcomes. He also holds the SAP Business Associate certification. 


\section{Introduction}

Gaming is one of the most popular forms of entertainment and recreational activities (Hartmann and Klimmt, 2006). Individuals are migrating from traditional forms of entertainment, such as TV, to more engaging and interactive pastime activities (Williams et al., 2008). Gaming can also act as a medium to promote learning and improve health. Designers have used video games to produce positive outcomes such as increasing the effectiveness of healthcare (Read and Shortell, 2011) and improving scholastic performance (Kiili, 2005b). Understanding the process through which a game can create a fun, rewarding, and enjoyable experience has been the focus of research in game studies (Cowley et al., 2008).

Games have been shown to be extensively engaging and are motivating players to spend much of their time with their favourite games (Charlton and Danforth, 2007). Involvement in games through the use of video games has become pervasive by people from all ages and genders (Williams et al., 2008). Game players can spend a significant amount of time playing games, and at times forget about other tasks and obligations. During gameplay, individuals may experience a deep level of engagement referred to as flow.

Flow (Csikszentmihalyi, 1990, 1997) is a state of optimal experience where one is completely absorbed and immersed in an activity. Flow plays an important role in understanding engagement and positive experience in the context of gaming. When a gamer experiences the state of flow while playing a game, he or she not only experiences a high level of engagement, involvement, and immersion in the game, but also loses track of time during gameplay. Flow is a state of mind in which an individual enjoys the activity immensely. This experience, or state of mind, can be observed among many game players, which is an ideal experience for game designers to facilitate for players of their games. Game designers have struggled with finding methods for engaging players in games and have looked towards creating flow experiences of players during gameplay (Sweetser and Wyeth, 2005). Thus, understanding and synthesising studies of the underlying theoretical explanation for engagement in games is a critical realm of research.

In this paper, we synthesise findings from the literature to understand the flow phenomenon in gaming. Our research objectives are to:

1 identify current streams of research in the gaming context

2 understand the antecedents, dimensions, and outcomes of flow in the gaming context

3 propose a framework from a synthesis of the literature on flow and gaming that identifies the key antecedents, dimensions, and outcomes

4 highlight some of the key game design elements that can contribute to flow experiences in gaming.

We also provide research and practical implications as well as suggestions for future research.

In the following section, background and the theory of flow are discussed in more detail. We then present the methodology for the review as well as the findings from the synthesis of our review of the literature. Based on the review, we propose a framework to summarise the literature and offer recommendations for game design with the goal of 
creating flow in the gaming context. The last section of this paper provides conclusions, implications, and recommendations for future research.

\section{Background and theory}

Previous research has examined relevant factors of flow in gaming, which include antecedents, dimensions, and outcomes of flow. For example, antecedents of flow that previous scholars have studied range from attitude towards gaming and computer self-efficacy to types of games and game controllers (Bressler and Bodzin, 2013; Hong et al., 2012; Thin et al., 2011). The state of flow has been further represented with various dimensions, such as enjoyment, control, and concentration (Fang et al., 2013; Hsu, 2010). The consequences from the state of flow entail a wide range of positive and negative outcomes, from positive affect and enhancements in performance to gaming addiction (Chiang et al., 2011; Chou and Ting, 2003; Hsu and Lu, 2004). In addition, researchers have proposed various models for evaluating flow in the gaming context (e.g., Cowley et al., 2008; Sweetser and Wyeth, 2005).

Most of the research draws on flow theory (Csikszentmihalyi, 1990, 1997), which provides the theoretical foundation for studying optimal experience in gaming. Flow theory is a prominent theory among game researchers for studying engagement and involvement of players during gameplay (Sweetser and Wyeth, 2005).

\subsection{Theory of flow}

Flow theory (Csikszentmihalyi, 1990, 1997) describes the phenomenon of optimal holistic experience where individuals enjoy and are immersed in an activity to the extent that they lose track of time and nothing else seems to matter to them. The experience can take place in a wide variety of daily activities, including dancing, participating in sports, performing surgery, or playing a game. For example, a child can get into flow while playing games and an adult can get into flow while browsing the internet, watching television, or playing a video game. Webster and Martocchio (1992, p.207) explained that when in a state of flow, "individuals become absorbed in their activities; their focus of awareness is narrowed, and they experience a sense of control over their environments". Earlier research has shown that the state of flow can be experienced through computer-mediated communication (Trevino and Webster, 1992), navigating in a 3D virtual world (Nah et al., 2011), online shopping (Novak et al., 2000), electronic learning (Choi et al., 2007), and online gameplay (Hsu and Lu, 2004).

Csikszentmihalyi (1997) explained that in order to experience flow, a task should satisfy three key conditions of having clear goals, unambiguous feedback, and a balance of challenges and skills. However, these three conditions are not the only components during the state of flow. According to Csikszentmihalyi (1990), people described their optimal experience to be comprised of at least one of the following eight components:

1 Challenging activity that requires skills: One of the key requirements for experiencing flow is to have skills and challenges of the activity in balance with each other. This balance defines the boundary between boredom (which occurs when skills are much higher than the challenge posed) and anxiety (which occurs when skills are inadequate and the task is perceived as being too challenging). 
2 Merging of action and awareness: When a person is in flow, he or she becomes totally involved/engaged in the task to the extent that the task becomes part of himself/herself and performing it is almost automatic and spontaneous.

3 Clear goals: Regardless of the type of task, the goals must be unequivocal for flow to take place.

4 Immediate feedback: Having an immediate and unambiguous feedback mechanism in an activity allows a person to evaluate performance and improvement towards the goal of the task.

5 Concentration on task at hand: One of the important characteristics of the state of flow is focusing attention on the task to the point where other thoughts are removed and distractions are ignored while attending to the task.

6 Paradox of control: Once a person is in flow, he or she would develop a belief of being in complete control of his or her own actions. The person, therefore, may not think of any possible mistakes and could partake in an activity that could even be harmful or dangerous if a mistake happens.

7 Loss of self-consciousness: A person ceases thinking about his or her own self due to being pre-occupied with an activity and loses his or her self-awareness.

8 Transformation of time: Optimal flow is experienced when a person loses track of time and his or her perception of time is distorted.

\subsubsection{Self-rewarding or autotelic experience}

Although not explicitly included in the components of flow noted above, Csikszentmihalyi (1990) also discussed another notion called 'autotelic experience'. Autotelic refers to a form of intrinsic motivation (Deci and Ryan, 1985), which explains the nature of behaviour that is originated merely for its own sake rather than to achieve an external goal or reward. In other words, carrying out the activity itself is self-rewarding and is the goal in and of itself. Although Csikszentmihalyi (1990) views flow as an autotelic experience, other scholars (such as Procci et al., 2012; Wang et al., 2009) have considered autotelic experience as one of the dimensions of flow.

Because of the importance of flow during gameplay, research has taken a particular interest in studying the flow phenomenon in the gaming context. Games provide the necessary feedback and clear goals that a person would need to experience flow (Fang et al., 2013). Also, games have the potential to be adaptive to the player's skills by modifying the challenges, thus creating a perfect balance of challenges and skills (Bressler and Bodzin, 2013). Challenges can assist in the enhancement or development of skills, and acquiring the requisite skills can lead to enjoyment of the game and advancing to successive, more challenging levels. If one's skill is not sufficient, then the game can cease being fun and obstruct the flow experience. 


\section{Synthesis of flow and gaming literature}

This paper focuses on reviewing and synthesising flow and gaming literature. We are interested in identifying existing streams of research as well as the antecedents, dimensions, and outcomes of flow in a gaming context. To accomplish this, we identified a set of published journal articles for inclusion in this review.

\subsection{Selection criteria of journal articles for review}

We utilised the following databases for identifying journal articles to be included in this review: ABI/Inform, Business Source Premier, PsycInfo, IEEE, ACM Digital Library, Academic Search Complete, and Scopus. Only journal articles that are published in English were included. For our selection criteria, we included journal articles that had the word 'flow' in the title along with one or more of the following terms: 'game', 'games', 'gamer', 'gamers', or 'gaming'. More specifically, the search query that was used is as follows:

TI('flow') AND TI('game' OR 'games' OR 'gamer' OR 'gamers' OR 'gaming')

Based on the above selection criteria, we identified 39 articles which will be discussed next.

\subsection{Synthesis of literature review}

Among the 39 articles included in this review, four are conceptual papers and the rest (i.e., 35 articles) are empirical papers. Table 1 provides a summary of the four conceptual papers. Table 2 provides a summary of the empirical papers.

Chen (2007) discussed the concept and relevance of flow in the context of gaming. He highlighted the importance of balancing the challenge posed by the game and the ability (or skill) of the player in order for the player to experience flow. When the challenge is higher than the player's ability, the player becomes anxious and cannot enter the flow state. When a player's skill is higher than the challenge posed by the game, the player is likely to get bored with the game and unlikely to experience flow. Chen also indicated that player characteristics (e.g., hardcore versus novice players) can influence their flow zone, i.e., the zone or area representing the relationship between challenge and ability where flow is present. Hence, the flow zone can differ across players.

Sweetser and Wyeth (2005) proposed the GameFlow model to evaluate player enjoyment in games. Based on the flow components identified by Csikszentmihalyi (1990), Sweetser and Wyeth (2005) proposed eight components that are important for gameplay - concentration, challenge, player skills, control, clear goals, feedback, immersion, and social interaction - and identified a set of criteria for them. Examples of criteria include "players should not be distracted from tasks that they want or need to concentrate on" (p.5) for the concentration component, "players should receive feedback on progress toward their goals" (p.6) for the feedback component, and "players should become less aware of their surroundings" (p.6) for the immersion component (Sweetser and Wyeth, 2005). 
Table 1 Summary of conceptual papers

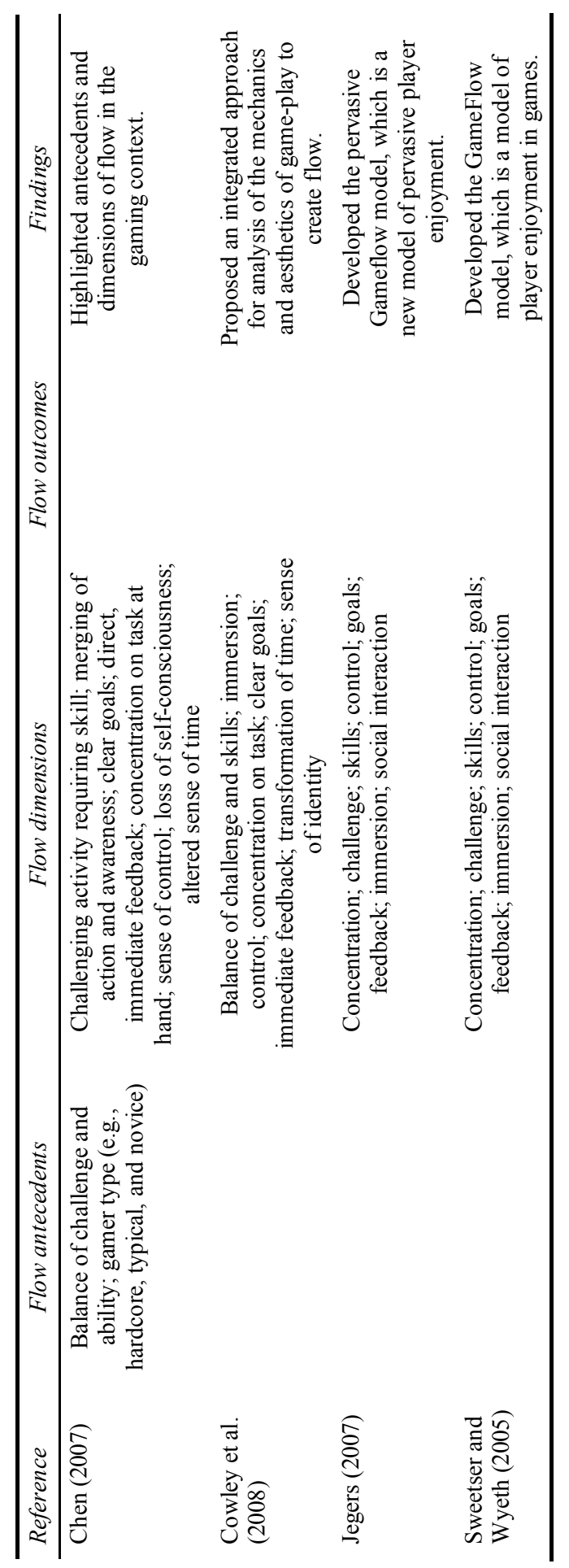


Table 2 Summary of empirical papers

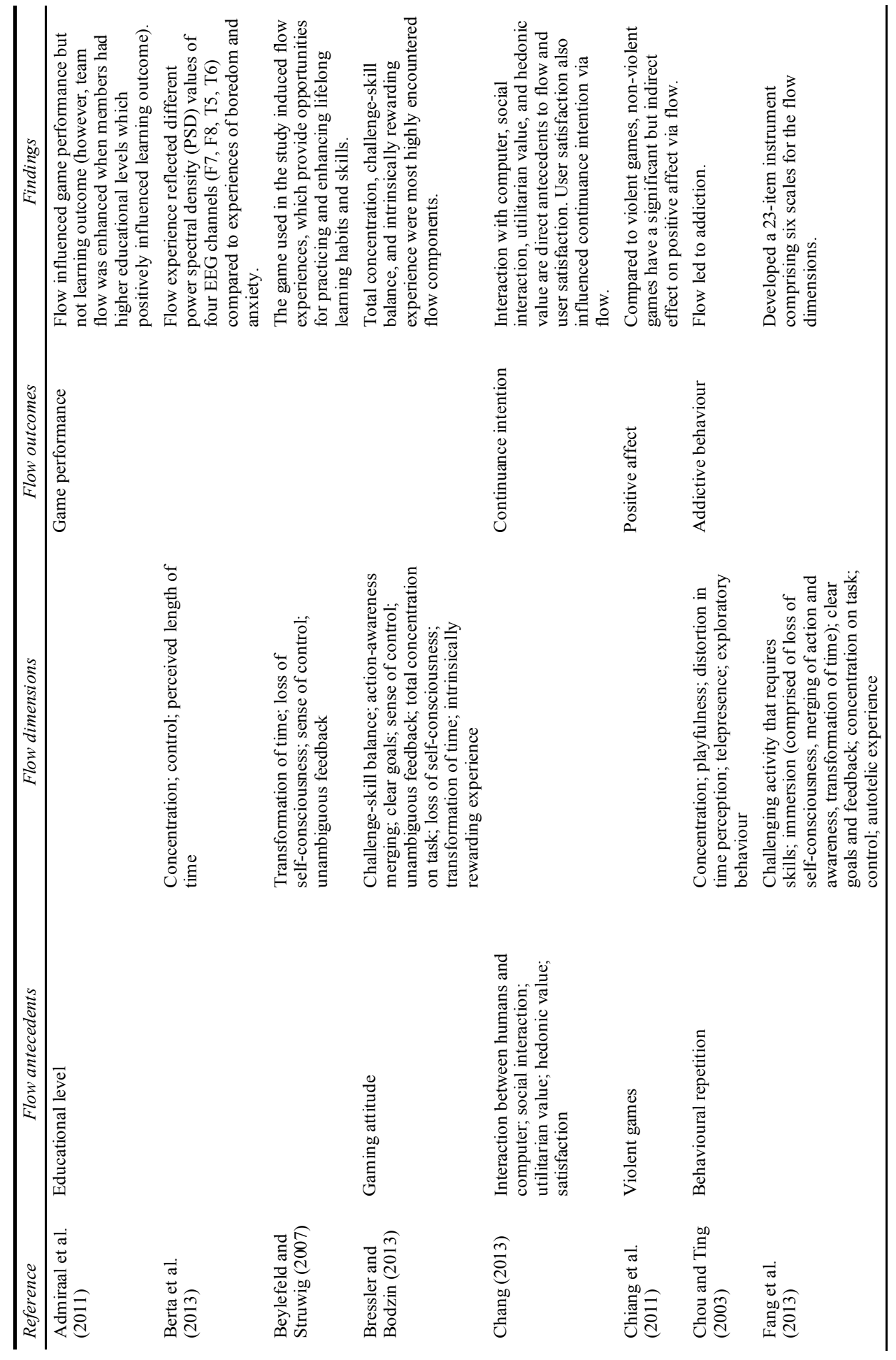


Table 2 Summary of empirical papers (continued)

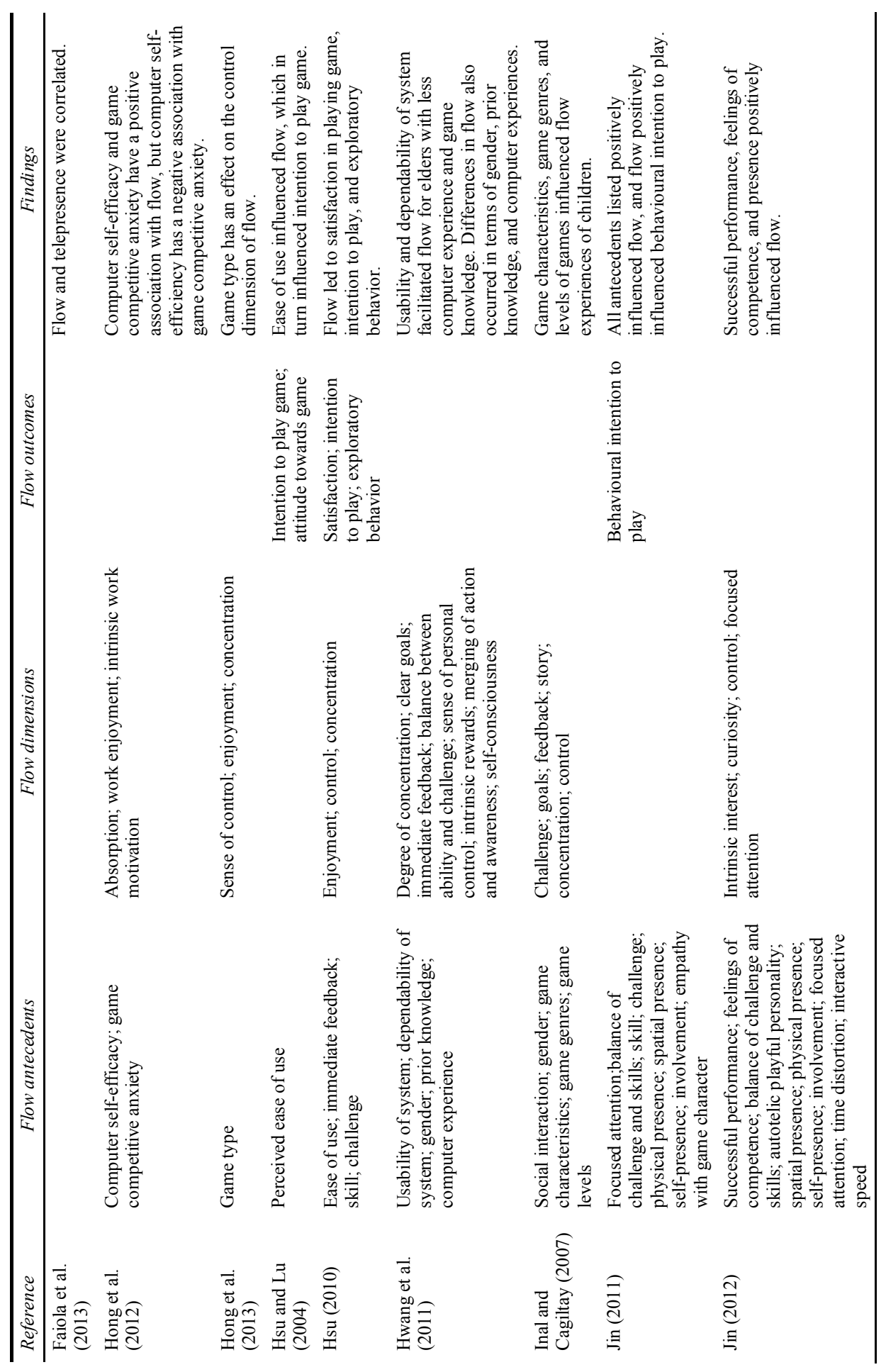


Table 2 Summary of empirical papers (continued)

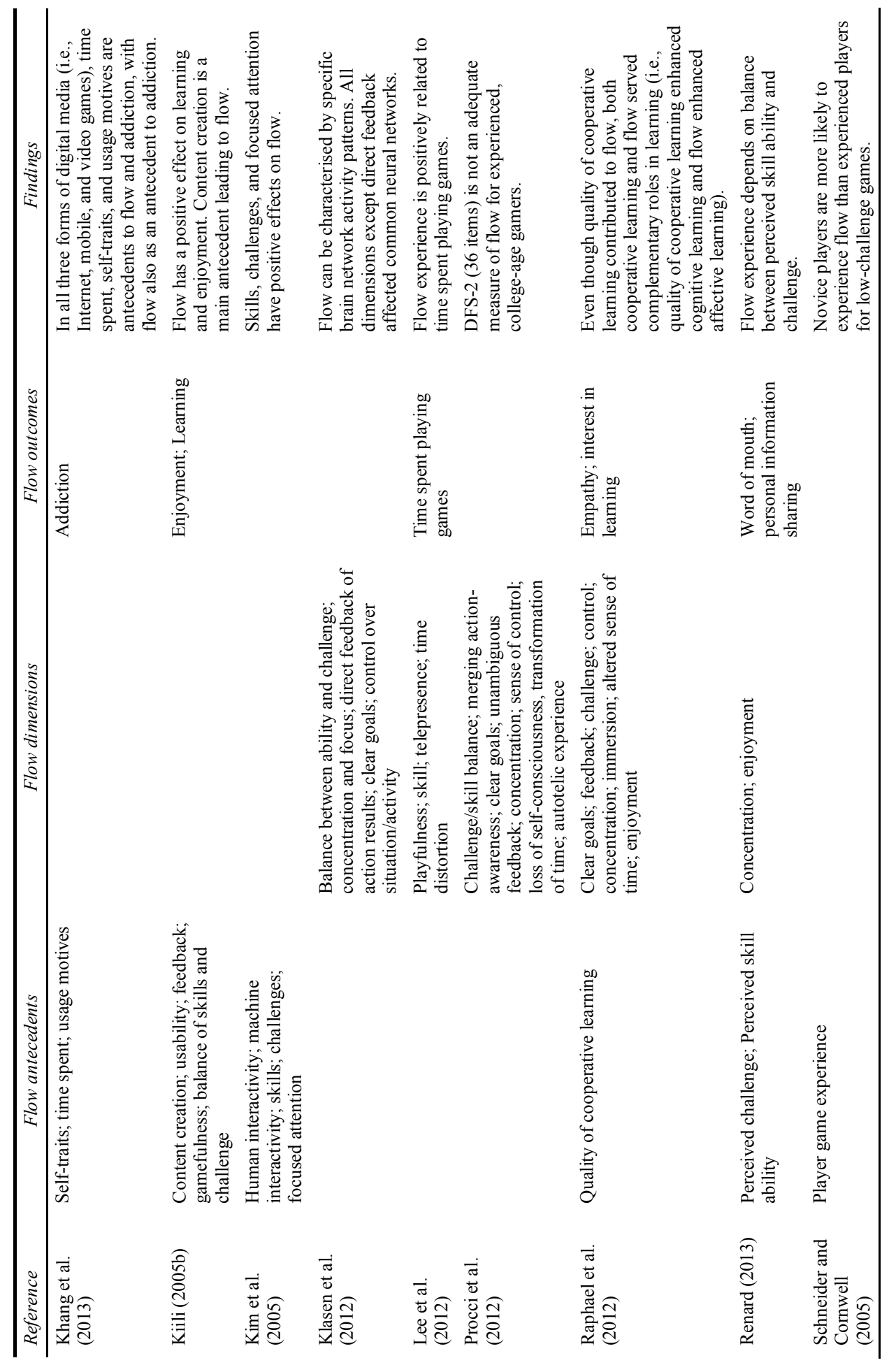


Table 2 Summary of empirical papers (continued)

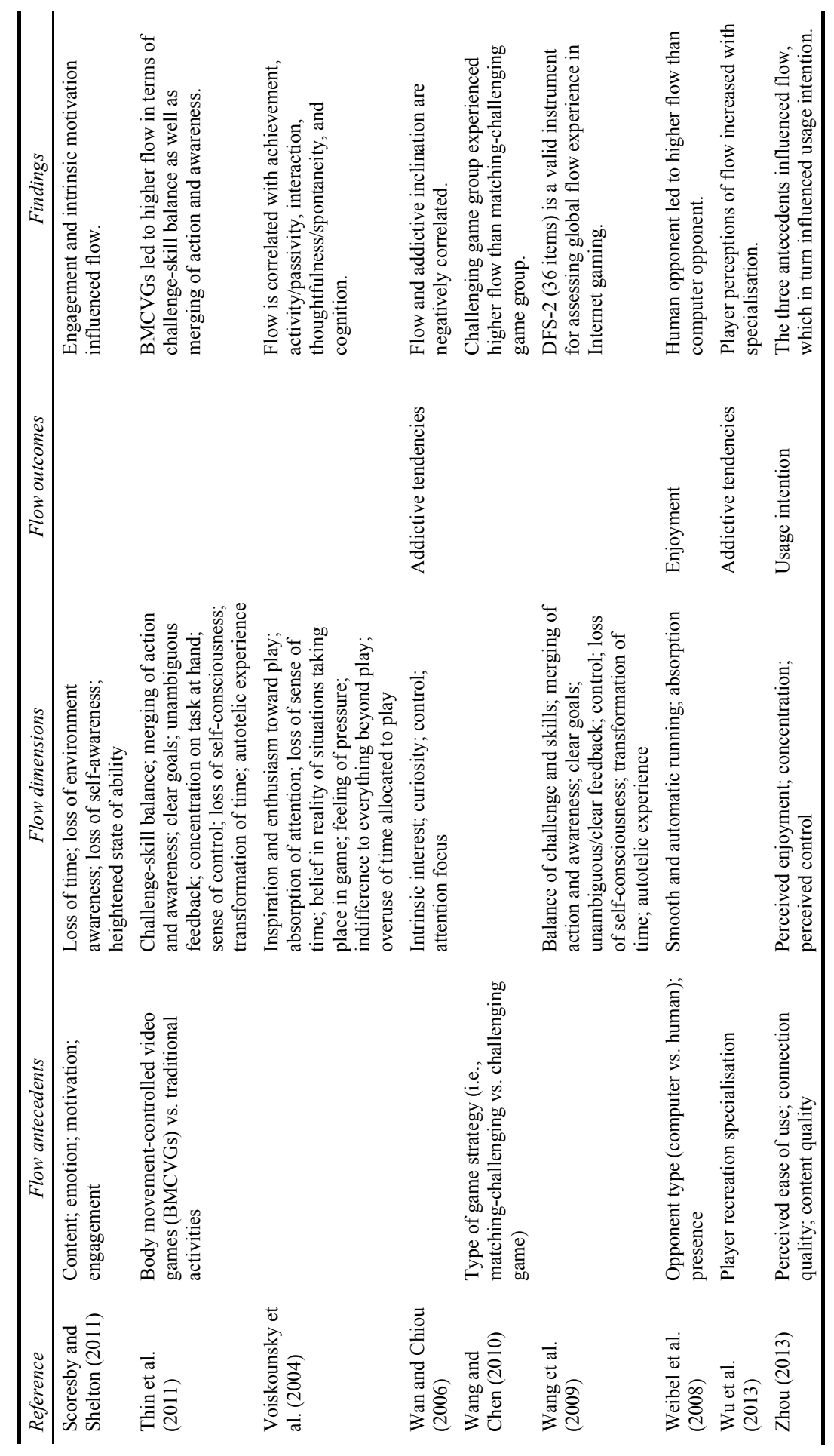


Jegers (2007) extended the GameFlow model based on the same set of eight criteria and proposed a new model of pervasive player enjoyment, the pervasive GameFlow model. A pervasive gaming context is characterised by "mobile/place-independent gameplay, social interaction between players, and integration of the physical and virtual worlds" [Jegers, (2007), p.4]. Cowley et al. (2008) utilised the user-system-experience (USE) framework to analyse the relationships between player and game structure, and proposed gameplay elements for inducing flow. For example, gameplay elements include plot lines and levels (corresponding to the flow element of clear goals) as well as appropriate rewards and penalties (corresponding to the flow element of immediate feedback).

Table 2 provides a summary of the 35 empirical papers included in this review.

The empirical papers summarised in Table 2 can be grouped and discussed under nine themes:

1 gaming in learning and education

2 presence

3 adoption

4 addiction

5 neural correlates of flow

6 measurement of flow

7 e-marketing

8 interactivity

9 nomological network for flow.

\subsubsection{Gaming in learning and education}

Advancements in the field of technology have brought enormous changes in the field of gaming and education. Digital games have become a feasible option for enhancing and developing e-learning tools. Several articles in our review address the use of gaming in education (Admiraal et al., 2011; Beylefeld and Struwig, 2007; Bressler and Bodzin, 2013; Faiola et al., 2013; Hong et al., 2013; Inal and Cagiltay, 2007; Kiili, 2005b; Raphael et al., 2012; Scoresby and Shelton, 2011; Wang and Chen, 2010).

In the context of collaborative game-based learning, team flow (i.e., flow experience in a team) has a positive effect on game performance outcomes but no effect on learning outcomes (Admiraal et al., 2011). Instead, a positive effect is found between competitiveness and learning outcomes when distractors (e.g., technology issues) were minimal (Admiraal et al., 2011). The findings also indicate that having team members of higher educational levels contribute positively to team flow and learning outcomes.

Beylefeld and Struwig (2007) studied the use of an online version of a quiz-style board game to enhance student learning in medical microbiology. The game served as a 'positive external challenge' where positive feedback and friendly competitions initiated flow among students, which increased their focus and urged them to acquire skills and accomplish their goals. The experience is believed to enhance their lifelong learning habits. 
Bressler and Bodzin (2013) found that the three most highly encountered flow components in a mobile augmented reality science game were total concentration, challenge-skill balance, and an intrinsically rewarding experience. Gaming attitude influences flow, but not gender or interest in science. Discovering new challenges kept players in flow, and the interdependent nature of collaboration in gameplay can increase flow.

Faiola et al. (2013) examined flow and telepresence in the context of game-based learning and found them to be correlated. Hong et al. (2013) examined learning retention in the context of two types of games: a slow and deliberate game called solitary versus a fast and automatic game called heart attack. The dual process theory suggests that these two types of games trigger different cognitive processes, i.e., slow and deliberate process for the solitary game, and fast and automatic process for the heart attack game. A lower sense of control was perceived in the heart attack game than in the solitary game because of the quick hand movements needed in the heart attack game.

Digital games have been adopted and used by all age groups (Hwang et al., 2011). In the context of improving elderly individuals' technology usage, research results indicated that system usability and dependability could help elderly individuals with minimal computer experience or knowledge of the game to experience flow (Hwang et al., 2011). The usability of a system refers to the degree to which the product can be accessed by its users, whereas the dependability of a system refers to the extent that a system can be trusted to operate free of failure. Also, elderly males preferred solitary gameplay while elderly females preferred to play with others.

Inal and Cagiltay (2007) examined children's flow experiences in an interactive social game environment. The results indicate that gender played an important role in flow experiences with more boys experiencing flow than girls during gameplay. Social interaction, game characteristics, game genres, and levels of games also influenced flow experiences. The flow experiences of boys were influenced mainly by the ludology of the game (i.e., rules and gameplay), while the flow experiences of girls were largely influenced by the narratology of the game (i.e., story and themes).

Kiili's (2005b) case study examined the use of a web-based educational game, IT-emperor, that offered content creation to facilitate active learning. Content creation was noted as the main activity that induced flow, while poor usability and the lack of gamefulness (i.e., game-like functionality) decreased flow. Flow also enhanced learning and enjoyment.

In game-based learning, Raphael et al. (2012) found no differences in flow between individual players and teams (consisting of two players). However, those teams that were more effectively cooperating to learn (i.e., cooperative learning) experienced higher levels of flow in comparison to those who were less cooperative. Also, teams that were more engaged in cooperative learning had more positive learning outcomes in comparison to teams that were less cooperative as well as individual players. Flow did influence empathy and interest in continued learning.

Using an experiential gaming activity in a $2 \times 2$ experimental design, Wang and Chen (2010) studied the effects of game strategy and preference-matching on the flow experience and performance of novices in learning to programme. The two types of game strategy are the matching-challenging strategy and the challenging strategy, where the former involved the use of matching and challenging games and the latter involved the use of challenging games only. With regard to preference matching, the matched group 
was comprised of those who preferred a challenging game while the mismatched group did not like challenge. The results indicate that the challenging group experienced higher flow experiences than the matching-challenging group, and matching learners' challenging game preference has no effect on flow experiences but has a positive effect on performance.

\subsubsection{Presence}

According to Steuer (1992), presence refers to "the sense of being in an environment" (p.75) and telepresence refers to "the extent to which one feels present in the mediated environment, rather than in the immediate physical environment" (p.76). In a gaming context, telepresence has been included in flow research models as an antecedent in some models and as a dimension of flow in others.

Faiola et al. (2013) argue that factors that influence telepresence include vividness, system responsiveness, as well as authenticity and richness of the mediated environment. Conducted in a 3D virtual world environment, their research found a significant relationship between flow and telepresence.

Jin (2011) identified three aspects of presence:

1 spatial presence (i.e., perceptions of being relocated into the virtual environment)

2 physical presence (i.e., virtual objects are perceived as real)

3 self-presence (i.e., associating one's virtual self with one's real self).

Jin (2011) found spatial presence, physical presence and self-presence to be antecedents to the flow experience in a variety of game genres. The results also indicated that highly skilled individuals experienced flow congruent with the level of challenge (i.e., highly challenging games resulted in heightened levels of flow, whereas games with low challenge resulted in low levels of flow). Individuals with low levels of skills did not experience flow regardless of the level of challenge. Individuals with medium levels of skill experienced the greatest sense of flow when the challenge was matched to their skill set (i.e., medium level of challenge) and experienced low flow when the challenge was not matched (i.e., low and high levels of challenge). Focused attention, involvement, and empathy with the game character influenced flow, which in turn explained behavioural intention.

A subsequent study by Jin (2012) also found spatial presence, physical presence, and self-presence to positively influence flow. The findings indicate that individuals who were successful at winning the games and felt competent in playing the games experienced greater levels of flow. Jin's (2011) findings regarding the balance of skill and challenge positively influencing flow were replicated in Jin's (2012) study. In addition, Jin (2012) found that individuals with greater playfulness experienced greater flow when a balance of skill and challenge was achieved. Also, focused attention, time distortion and interactive speed are predictors of flow (Jin, 2012).

Scoresby and Shelton (2011) found enjoyment of game content, emotion, intrinsic motivation, and engagement to be important factors that influence presence and flow, with the first three factors being necessary before engagement could be experienced. Although the main purpose of the study was to assess the effect of viewing perspective (e.g., first-person perspective where vision is relative to one's own body, third-person perspective where one controls one's character in the game like a 'puppet'), it was found 
that the above four factors have greater influence on presence, flow, and learning than the viewing perspective.

Weibel et al. (2008) argue that flow and presence have some commonalities, but also some distinctive differences. Both flow and presence are associated with feelings of being immersed and highly involved in an activity. However, presence refers to "immersion into a virtual environment" [Weibel et al., (2008), p.2278], while flow refers to "an experience of immersion into a certain activity" (p.2278). It was found that participants who played against human-controlled opponents experienced higher levels of presence, enjoyment, and flow than those who played against computer-controlled opponents. Additionally, flow has been demonstrated to mediate the relationship between presence and enjoyment.

\subsubsection{Adoption}

An important aspect of gameplay, user experience, plays a crucial role in determining user adoption of games. Similarly, flow experience has an impact on user adoption in the gaming context (Chang, 2013; Hsu, 2010; Hsu and Lu, 2004; Jin, 2011; Zhou, 2013). In a study by Chang (2013) on social network gaming, four factors - interaction between humans and computer, social interaction, hedonic value, and utilitarian value - were demonstrated to be antecedents of flow and user satisfaction, where both of them in turn influenced continuous intention. In addition, user satisfaction also influenced flow.

Hsu (2010) demonstrated empirically that intention to play is an outcome of flow. Building on the technology acceptance model (TAM) (Davis, 1989), Hsu and Lu (2004) extended TAM by showing that perceived ease of use is an antecedent of flow and intention to play an online game is an outcome of flow. Additionally, social norms and perceived critical mass are two social factors that influenced intention to play.

Similar to Chang (2013) as well as Hsu and Lu (2004), Jin (2011) also demonstrated that flow has an effect on behavioural intention, where the higher the level of flow experienced, the greater one's intention to adopt or play a game. Although Zhou's (2013) study was conducted in the mobile gaming context, the findings are similar to those by Hsu and $\mathrm{Lu}$ (2004) in that both found flow to mediate the relationship between perceived ease of use and adoption intention. In both studies, social factors [i.e., social influence in the case of Zhou (2013), and social norms and perceived critical mass in the case of Hsu and $\mathrm{Lu}$ (2004)] have an effect on usage intention. Zhou (2013) found connection quality of mobile service and content quality to influence flow in mobile gaming, which in turn influenced mobile game usage intentions.

\subsubsection{Addiction}

Addictive behaviour is another possible outcome that can result from flow (Chou and Ting, 2003; Khang et al., 2013; Wan and Chiou, 2006; Wu et al., 2013). Flow experience and repetitive behaviour have been shown to positively influence addiction (Chou and Ting, 2003). However, flow is found to have a direct influence on addiction, and repetitive behaviour is best modelled as an antecedent of flow. Also, flow has been found to positively influence individuals' obsessiveness, extensive time playing games, and preoccupation with gaming.

Khang et al.'s (2013) study focused on flow and addiction associated with three forms of digital media usage (i.e., internet, mobile, and video games). Pastime (i.e., using a 
medium during one's free time to avoid boredom) is positively related to flow and addiction for all three media types. Self-presence (i.e., impressing others) was positively related to addiction for all three media types, but was positively related to flow only for internet and mobile phone usage. Self-control was negatively related to flow and addiction for all three media types (i.e., lower self-control was associated with higher levels of flow and addiction), and self-efficacy was negatively related to addiction for mobile phone usage. However, self-esteem was not related to flow or addiction for any of the media types. Other factors influencing addictions included information seeking influencing addictions with video games and social relationship (i.e., socialising) influencing addictions with mobile phones. Flow was found to influence addictions for all media types.

According to $\mathrm{Wu}$ et al.'s (2013) finding, the more specialised a player in gaming (e.g., seeking methods to improve or advance play, joining gaming associations), the more flow and addictive tendencies experienced, with specialisation also being a moderator of the relationship between flow and addictive tendencies. Hence, the impact of flow on addictive tendencies was found to be more salient for highly specialised players in comparison to those players with lower degrees of specialisation. Contradicting these findings, however, Wan and Chiou (2006) found a negative relationship between flow and addictive tendencies, where gaming addicts experienced less flow than non-addicts. Also, they found that flow did not predict future addiction. Wan and Chiou (2006) contradicted other researchers' point of view that a satisfied player is more likely to become an addict. Based on their findings, they suggest that "compulsive use of online games comes from the relief of dissatisfaction rather than the pursuit of satisfaction" [Wan and Chiou, (2006), p.323].

\subsubsection{Neural correlates}

Neural correlates for the flow experience were studied by Berta et al. (2013) and Klasen et al. (2012). Berta et al. (2013) studied the use of electroencephalogram (EEG) for user status monitoring in games. A special characterisation of video-gaming experiences was performed. The results indicate that the flow experience reflects different power spectral density (PSD) values of four EEG channels (F7, F8, T5, T6) compared to experiences of boredom and anxiety (Berta et al., 2013). The goal of Klasen et al.'s (2012) study was to explain the following five flow components using fMRI: balance of challenge and skill, focused attention, immediate feedback, unambiguous goals, and perceptions of control. Flow components were detected by specific brain network activity patterns. All components of flow, except direct feedback, affected common neural networks.

\subsubsection{Measurement of flow}

Among the set of papers reviewed, three of them focus on measurement of flow (Fang et al., 2013; Procci et al., 2012; Wang et al., 2009). Based on Csikszentmihalyi's components of flow, Fang et al. (2013) compiled validated scales and items for each of them from a review of relevant studies, used the card-sorting method (Moore and Benbasat, 1991) to cleanse the scales and items, and carried out factor analysis on them. Six components emerged from the factor analysis, suggesting that flow can be assessed through six scales: 
1 balance of challenge and skill

2 immersion (which is comprised of merging of action and awareness, loss of self-consciousness, and transformation of time)

3 clear goals and feedback

4 concentration on the task at hand

5 paradox of control

6 autotelic experience.

Procci et al. (2012) and Wang et al. (2009) assessed the psychometric properties of flow in gaming using the dispositional flow scale-2 (DFS-2) developed by Jackson and Eklund (2002). Interestingly, Wang et al.'s (2009) analysis indicate that DFS-2 is a valid instrument for assessing global flow experience in internet gaming whereas Procci et al. (2012) concluded that DFS-2 is not an adequate measure for capturing the state of flow of experienced, college-age gamers. Procci et al. (2012) provided several possible reasons for the difference between their findings and those by Wang et al. (2009). Because Procci et al. (2012) used older (college-age) students who were experienced gamers as subjects and Wang et al. (2009) used elementary students who might not have experience with internet gaming as subjects, the difference could have arisen due to gaming experience or age. In addition, Procci et al. (2012) noted the possibility that Wang et al.'s (2009) subjects, being elementary students, may not fully understand the complex wording in many of the items. Thus, more research is needed to assess whether DFS-2 is relevant for capturing flow in video gaming since the scale was originally developed for measuring flow in sports, which is a highly physical rather than cognitive activity.

\subsubsection{E-marketing}

In a promotional social game context, the players' flow experience was determined by the balance of perceived skill ability and perceived challenge (Renard, 2013). The flow experience was highest when both perceived skill ability and challenge were high. In addition, flow experience led to increased occurrences of word-of-mouth and personal information sharing, both of which contributed to marketing and promotions. Hence, flow is an important factor in the success of advergames (i.e., games that are developed for the purpose of advertisement).

Schneider and Cornwell (2005) conducted a study to examine the relationships between computer game experience, flow, and user recall and recognition of brand placements in video games. It was found that experienced players were less likely to enter the flow state than novice players, which could be because of the low-challenge task used in the study. Interestingly, the results indicate that individuals who experienced flow during the game did not exhibit higher recall or recognition of brand names compared to individuals who did not experience flow.

\subsubsection{Interactivity}

Interactivity refers to the "degree to which users of a medium can influence the form or content of the mediated environment" [Steuer, (1992), p.80]. Kim et al. (2005) examined two aspects of interactivity in a gaming context: 
1 human interactivity - interactivity with other humans through the game

2 machine interactivity - interactivity with the medium of the game.

Human interactivity and machine interactivity have an indirect impact on flow through the degree of challenges posed by the game and the skills of the players. In other words, interacting with other humans in a game, such as through competition or cooperation, can help one to overcome challenges posed by the game or acquire skills or knowledge relating to the game. In addition, interactivity with the game, such as through informational cues offered by the game or additional features to increase one's control of the game, also helps to enhance one's skills or overcome challenges posed by the game. Weibel et al. (2008) found human-controlled opponents to bring higher flow experiences to players than computer-controlled opponents, which could be attributed to the increased challenges and opportunities for skill advancement offered by the game.

Thin et al. (2011) conducted a comparative study between body movement-controlled video games (BMCVGs) and traditional exercises, and reported that BMCVGs resulted in higher flow levels in terms of challenge-skill balance and merging of action and awareness. They also indicate that a player's involvement in a game in terms of time spent on the game is dependent on the game's challenges matching the player's skills.

\subsubsection{Nomological network for flow}

Several other articles assessed a variety of nomological networks for flow to better understand contributing and consequential factors of flow (Chiang et al., 2011; Hong et al., 2012; Hsu, 2010; Lee et al., 2012; Voiskounsky et al., 2004).

Chiang et al. (2011) examined the effect of violent versus non-violent games on players' flow experiences, positive affect, and aggression. The findings indicate that non-violent games created higher levels of flow experiences than violent games, and the heightened flow experiences triggered positive affect. Interestingly, violent and non-violent games have no effect on aggression.

A player's state of flow can also be influenced by user characteristics such as computer self-efficacy and competitive anxiety (Hong et al., 2012). Furthermore, Lee et al. (2012) found self-concept clarity to be negatively associated with time spent playing games. They also found flow to be associated with time spent playing games but did not hypothesise any direct relationship between self-concept clarity and flow.

Hsu (2010) found perceived ease of use, immediate feedback, skill, and challenge to be antecedents of flow, and satisfaction, intention to use, and exploratory behaviour to be outcomes of flow in the gaming context. Voiskounsky et al. (2004) carried out a correlational study of flow that has implications for nomological networks for flow. In a survey on behaviour of players in multi-user dungeons, or multi-user dimensions (MUDs), it was observed that flow has high positive correlations with achievement and cognition, suggesting that the flow experience is congruent with the matching of challenges and skills, and players' cognition is high when flow is present.

Based on a thorough analysis and synthesis of the literature on flow in gaming, we developed a framework for flow in gaming which is presented next. 


\section{Development of a framework for flow in gaming}

Based on our review, we developed the framework in Figure 1 that presents the antecedents, dimensions, and outcomes of flow in the gaming context and provide discussions for them.

Figure 1 Framework for flow in gaming

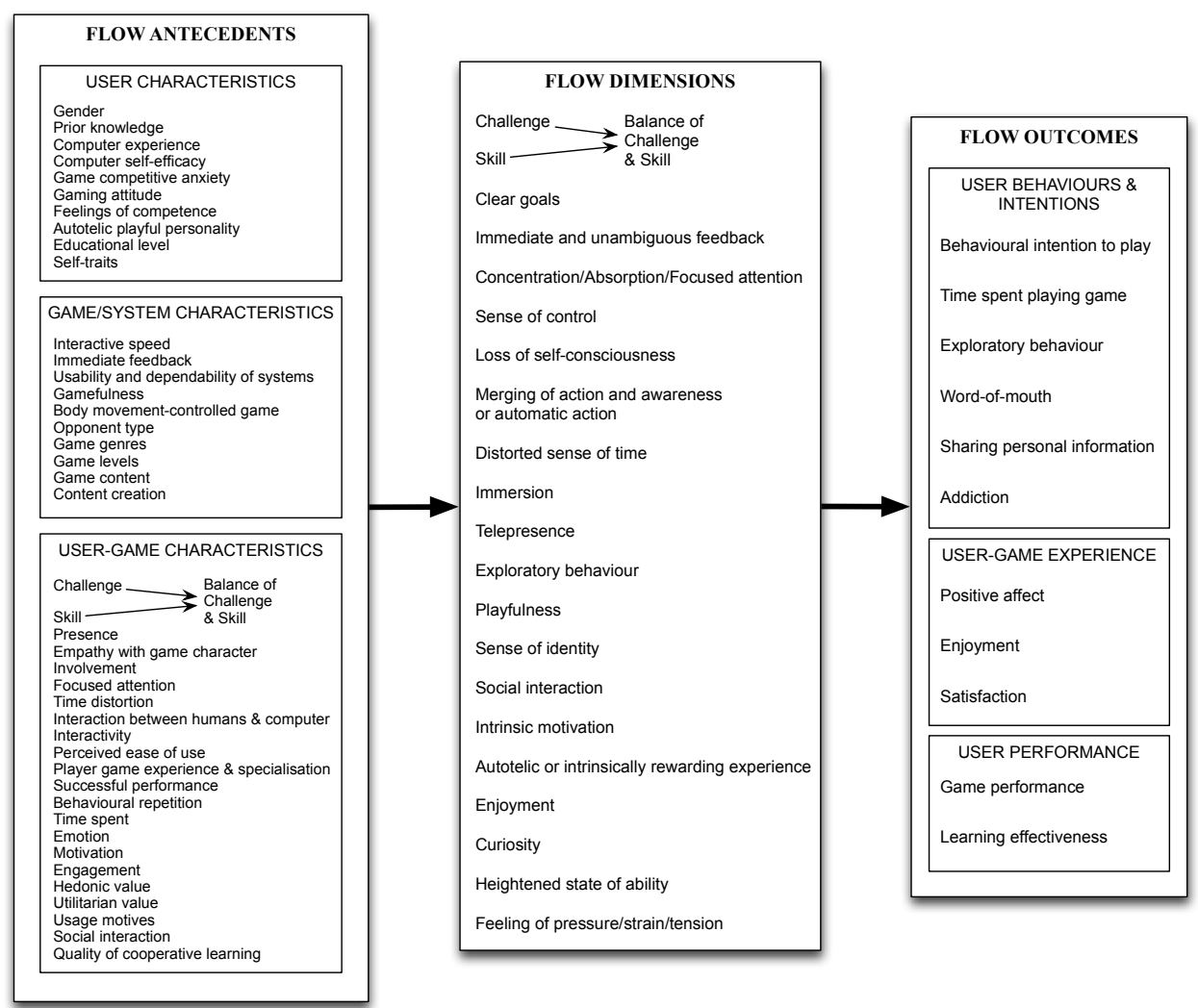

\subsection{Flow antecedents}

Our review identified three sets of antecedents of flow:

1 user characteristics

2 game/system characteristics

3 user-game characteristics.

Each of these is discussed below. 


\subsubsection{User characteristics}

Several user characteristics have been identified to influence flow experiences. These characteristics include:

1 gender

2 prior knowledge

3 computer experience

4 computer self-efficacy

5 game competitive anxiety

6 gaming attitude

7 feelings of competence

8 autotelic playful personality

9 educational level

10 self-traits (self-esteem, self-efficacy, and self-control).

Gender has been shown to have an impact on flow experiences (Hwang et al., 2011). For example, elderly females preferred playing with others while elderly males preferred playing alone. In the case of females, sharing helped females to get into the flow state, while satisfying one's self-interests through playing alone helped males to experience flow. In another study, Inal and Cagiltay (2007) reported more boys experienced flow than girls in an interactive social game environment.

Prior knowledge of the game and its contents have also been demonstrated to be predictors of flow (Hwang et al., 2011). Interestingly, previous computer experience was interruptive to participants' interaction with the game. Participants had to adapt to a new method of playing an embodied interactive video game which was dissimilar to previous computer interactions (Hwang et al., 2011).

Computer self-efficacy is a concept derived from self-efficacy, which is the perception of one's own ability (Bandura, 1977). The literature on social cognitive theory suggests that self-efficacy positively affects performance (Bandura, 1977, 1986). Hong et al. (2012) found computer self-efficacy to have a positive effect on flow. In addition, game competitive anxiety, which is an emotional and cognitive reaction that occurs when competition is viewed as a threatening object, is found to have a positive effect on flow (Hong et al., 2012). Gaming attitude, which is one's attitude or enthusiasm towards games, has also been found to be an antecedent of flow (Bressler and Bodzin, 2013).

Feelings of competence and autotelic playful personality contribute to greater flow experiences (Jin, 2012). Playfulness is an inherent autotelic personality trait, where autotelic personality has been described as "a conjunction of receptive qualities (i.e., openness to new challenges) and active qualities (i.e., readiness to engage and persist in high-challenge activities) characterized by curiosity about meta-skills, interest in life, imagination and inventiveness" [Jin, (2012), p.173].

Educational level has been found to be an antecedent of flow in a study of collaborative game-based learning where team flow was assessed (Admiraal et al., 2011). The analysis indicated that educational level had a positive effect on team flow. In other 
words, having members of higher educational levels on a team increased the flow experience of the team.

Khang et al. (2013) examined the concept of self-traits in terms of self-esteem, self-efficacy and self-control, and assessed its effect on flow. Among the three components of self-traits, self-control dominated the effect on flow in all three types of media studied - internet, mobile and video games.

\subsubsection{Game/system characteristics}

Several game and system characteristics have been demonstrated to be antecedents of flow in the context of gaming. These characteristics are:

1 interactive speed

2 immediate feedback

3 usability and dependability of systems

4 gamefulness

5 body movement-controlled game

6 opponent type

7 game genres

8 game levels

9 game content

10 content creation.

Interactive speed refers to "the speed of gaming and controlling devices...in responding to game players' actions" [Jin, (2012), p.175]. In other words, interactive speed refers to the time lag between the gamer's action and the game's response. In gaming, interactive speed is an important determinant of flow (Jin, 2012). If the interactive speed is low, flow cannot be achieved. Immediate feedback, which is the extent to which the user perceives seamless response from the interaction of the game, is related to interactive speed because high interactive speed is necessary in order to achieve immediate feedback. Immediate or quick feedback is found to influence flow experience in gaming (Hsu, 2010; Kiili, 2005b).

System usability and dependability can facilitate users' flow experiences (Hwang et al., 2011). Hwang et al. (2011) found that system usability and dependability have enabled elderly individuals with little computer experience or prior knowledge to experience flow. As noted by Kiili (2005b), for flow to occur, the user interface needs to be transparent, or simple to use, such that attention is focused on the task and not the technology in order to allow players to concentrate and achieve their goals. Kiili's (2005b) study shows that achieving flow was problematic when difficulties with using the game or technology occurred and when gamefulness was perceived as low. Kiili (2005b) noted that educational games also need a good level of gamefulness, which refers to the use of game design elements such as leaderboards, levels, points, badges, and trophies (Nah et al., 2013). 
BMCVGs have become more and more popular in the multiple gaming console platform, such as in the case of exercise games. BMCVGs have been shown to lead to higher flow levels than traditional activities for the flow dimensions of challenge-skill balance and merging of action and awareness (Thin et al., 2011).

In the online gaming context, playing against human-controlled opponents can enhance interactivity and social competition which in turn can enhance immersion into the gaming environment. Playing against a human-controlled opponent was shown to give rise to higher levels of flow than playing against a computer-controlled opponent (Weibel et al., 2008).

Game types or genres and game levels can have an effect on flow (Chiang et al., 2011; Hong et al., 2013; Inal and Cagiltay, 2007). Players perceived a lower sense of control when playing the heart attack game which required fast and automatic response as compared to the solitary game which required slow and deliberate response (Hong et al., 2013). Violent versus non-violent games can also trigger different levels of flow experience (Chiang et al., 2011), where those playing non-violent games experienced more flow. Also, players experienced more flow when they were successful in passing higher and more difficult game levels (Inal and Cagiltay, 2007).

Game content can also have an effect on flow (Scoresby and Shelton, 2011; Zhou, 2013). According to Scoresby and Shelton's (2011) findings, content is a necessary factor for inexperienced players to achieve the flow state. For experienced players, the content could be ignored due to familiarity with the game. Content quality, which reflects the content appeal, timeliness, and reflection of users' preferences, is also important for achieving the flow state (Zhou, 2013).

Content creation challenge refers to addressing problems that require players to design and create content (Kiili, 2005b). In order to engage and enhance comprehension of material, individuals can produce or design the learning materials. Content creation was a significant factor contributing to the flow experience (Kiili, 2005b).

\subsubsection{User-game characteristics}

User-game characteristics are characteristics that exist based on user-game interaction. The antecedents of flow that fall into this category are:

1 challenge, skill, and balance of challenge and skill

2 presence

3 empathy with game character

4 involvement

5 focused attention

6 time distortion

7 interaction between humans and computer

8 interactivity

9 perceived ease of use

10 player game experience and specialisation 
11 successful performance

12 behavioural repetition

13 time spent

14 emotion

15 motivation

16 engagement

17 hedonic value

18 utilitarian value

19 usage motives

20 social interaction

21 quality of cooperative learning.

A balance of challenge and skill is a required condition to reach the flow state (Csikszentmihalyi, 1990). If a mismatch between challenge and skill occurs, the state of flow can be inhibited. As demonstrated by Jin $(2011,2012)$ and Renard (2013), the combination of a high level of challenge and a high level of skill resulted in the highest level of flow state. Interestingly, however, Wang and Chen (2010) found that challenging games induced more flow experiences than those that attempted to match game challenge to skills, although the latter demonstrated greater project performance.

Other researchers treat challenge and skill as independent constructs in studying their effect on flow (Hsu, 2010; Jin, 2011; Kim et al., 2005). Hsu (2010) and Kim et al. (2005) show that challenge and skill are direct antecedents of flow. Although Jin's (2011) study shows that skill directly influenced flow whereas challenge did not (i.e., challenge influenced flow indirectly through spatial and physical presence), the analyses also demonstrated an interaction between skill and challenge. Hence, support was provided for the influence that the balance of challenge and skill has on the flow experience. Kiili (2005b) identified problem solving in the form of challenges, with problems and stories in gaming, as an antecedent to flow.

Jin (2011) identified three types of presence - spatial presence, physical presence, and self-presence - and found that they induced the flow experience. All three types of presence were predictors of flow in music games and exergames (or fitness games) (Jin, 2012). In addition, empathy with a game character/avatar was found to influence flow through self-presence (Jin, 2011). Flow was also found to be influenced by involvement (Jin, 2011, 2012), focused attention (Jin, 2011, 2012; Kim et al., 2005), and time distortion (Jin, 2012).

A good or high quality interaction between humans and computers can be achieved through a well-designed interface. Chang (2013) shows that the interaction between humans and computers has a positive effect on flow. In addition, interactivity in the form of human interactivity (i.e., between players) and machine interactivity (i.e., between system and players) are found to influence skill, challenge, and focused attention, which are all significant predictors of flow in the online gaming context (Kim et al., 2005). Perceived ease of use has been found to positively influence flow experience as well (Hsu, 2010; Hsu and Lu, 2004; Zhou, 2013). 
Player game experience can also influence flow (Schneider and Cornwell, 2005). Although it is generally the case that highest flow is attained when game challenge and player skill are well balanced or matched (Jin, 2011, 2012; Renard, 2013), Schneider and Cornwell (2005) found that novice players experienced more flow than experienced players in low-challenge tasks. They concluded that the challenge presented by the game was not high enough for experienced players. Hence, the findings are consistent with the notion that balance of challenge and skill is important.

Player recreation specialisation is the degree to which one specialises in an activity as reflected by equipment and skills used in the activity. It includes cognitive, affective, and behavioural characteristics components (Wu et al., 2013). Player recreation specialisation was found to not only influence flow experience and addictive tendencies, but it also intensified the impact of flow on these addictive tendencies.

Successful performance is related to perceptions of competence in gaming and they are found to be antecedents of flow (Jin, 2012). Individuals participating in a game can receive positive feedback from successful performance which enhances their perception of competence, and thus increases their flow experience. In addition, behavioural repetition and time spent playing games are also predictors of flow (Chou and Ting, 2003; Khang et al., 2013).

Scoresby and Shelton (2011) identified emotion, motivation, and engagement associated with the game as necessary criteria for flow except in the case of experienced players who are able to connect emotionally with the game a priori. Emotion helps players to feel connected with the game or the game's characters (Scoresby and Shelton, 2011). Scoresby and Shelton concluded that emotion, such as empathy with game characters, positively affect flow experience, especially for inexperienced or novice players to get connected with the game. After a player is able to connect with the game emotionally, motivation is the next step in the process to satisfy the conditions for flow. Motivation in turn will trigger the player to become more involved in the game in order to experience engagement. In summary, intrinsic motivation and engagement are necessary conditions for getting into flow, even for experienced players (Scoresby and Shelton, 2011).

Chang (2013) identified hedonic value and utilitarian value as antecedents of flow. These values could serve as a form of intrinsic motivation to get players engaged in a game. Hedonic value refers to "an outcome related to spontaneous responses that are more subjective and personal...such as entertainment, exploration, and self-expression...and that derive more from fun and enjoyment than from task completion" [Chang, (2013), p.314]. Utilitarian value refers to "an overall assessment of the balance between functional benefits and sacrifices" [Chang, (2013), p.314]. Hedonic and utilitarian values have both direct and indirect effects on flow. In addition to the direct effect, hedonic and utilitarian values also increase the player's satisfaction with the game, which in turn further enhances flow.

In a study on addiction, it is found that media use motives contribute to flow (Khang et al., 2013). Among the four types of media use motives (i.e., information seeking, social relationships, pastime, and self-presence), pastime is the strongest predictor of flow (Khang et al., 2013). Social interaction also has been shown to have a positive effect on flow (Chang, 2013). In a study on game-based cooperative learning, it was found that the quality of cooperative learning is a key factor contributing to flow, which increases affective learning in terms of empathy and interest in learning (Raphael et al., 2012). 


\subsection{Flow dimensions}

Among the articles we reviewed that assessed flow using multiple dimensions, a variety of components by Csikszentmihalyi (1990) have been used. Fang et al. (2013) utilised Csikszentmihalyi's (1990) original flow components most faithfully by modelling the following dimensions of flow: challenging activity that requires skill, merging of action and awareness, clear goals, clear feedback, concentration on task at hand, paradox of control, loss of self-consciousness, transformation of time, and autotelic experience. Based on the results of factor analysis, Fang et al. (2013) combined clear goals and immediate feedback into one component called clear goals and feedback. Similarly, loss of self-consciousness, merging of action and awareness, and transformation of time also loaded onto one component referred to as immersion (Fang et al., 2013).

Sweetser and Wyeth (2005) also adapted Csikszentmihalyi's (1990) components but replaced autotelic experience with social interaction. Sweetser and Wyeth (2005) indicated that:

"The final element of player enjoyment, social interaction, does not map to the
elements of flow, but is highly featured in the literature on user-experience in
games. People play games to interact with other people, regardless of the task,
and will even play games they do not like or even when they don't like games
at all." (p.4)

Hence, social interaction was added. In addition to the components by Csikszentmihalyi (1990), Cowley et al. (2008) also identified sense of identity as a dimension of flow.

Various other researchers such as Hsu (2010) and Hwang et al. (2011) used only a subset of Csikszentmihalyi's (1990) components to measure flow. Hsu (2010) measured flow using concentration, control, and enjoyment, whereas Hwang et al. (2011) assessed flow dimensions using clear goals, concentration, balance (of challenge and skill), control, and intrinsic rewards/motivation. Intrinsic motivation (or intrinsic interest) was also identified by Hong et al. (2012), Jin (2012), and Wan and Chiou (2006) as a dimension of flow. Beylefeld and Struwig (2007) assessed flow using transformation of time, loss of self-consciousness, sense of control, and unambiguous feedback.

Telepresence has also been noted as a dimension of flow (Chou and Ting, 2003; Lee et al., 2012). Telepresence has often been used interchangeably with immersion (Lombard and Ditton, 1997). Perceptual immersion refers to "the degree to which a virtual environment submerges the perceptual system of the user" [Biocca and Delaney, (1995), p.57]. As noted earlier, telepresence refers to the perception that one is present in the mediated environment. Hence, immersion and telepresence have a complementary relationship. When one is immersed or feels telepresence in a mediated environment, one not only is unaware of the physical environment, including distractions in the physical environment, but also perceives the game as part of reality (Voiskounsky et al., 2004).

Several other dimensions of flow were suggested and assessed by researchers, including curiosity (Jin, 2012; Wan and Chiou, 2006), exploratory behaviour (Chou and Ting, 2003), playfulness (Chou and Ting, 2003; Lee et al., 2012), heightened state of ability (Scoresby and Shelton, 2011), and feeling of pressure/strain/tension (Voiskounsky et al., 2004).

In summary, there are no standard or agreed upon dimensions for flow based on the articles we reviewed. Researchers measured flow in a variety of ways using different sets 
of components or dimensions, which pose challenges when comparisons or aggregation of findings across studies are to be carried out.

\subsection{Flow outcomes}

Our review identifies three sets of outcomes of flow in gaming:

1 user behaviours and intentions

2 user-game experience

3 user performance.

\subsubsection{User behaviours and intentions}

Flow has been shown to have effects on user behaviours and intentions, which are:

1 behavioural intention to play

2 time spent playing game

3 exploratory behaviour

4 word-of-mouth

5 sharing personal information

6 addiction.

One of the consequences of flow experience is behavioural intention to play, or the tendency to play games in the future. Flow experiences contribute to a greater likelihood of playing a game again at some future point in time (Chang, 2013; Jin, 2011) and intentions to play a game (Hsu and $\mathrm{Lu}, 2004 ; \mathrm{Hsu}, 2010)$. Flow experience has also been found to have a positive impact on the amount of time spent playing games (Lee et al., 2012) as well as exploratory behaviour (Hsu, 2010). In the context of gaming, exploratory behaviour refers to "the degree to which the user is eager to check out new games and find out about the latest game just out of curiosity" [Hsu, (2010), p.54].

Renard (2013) found that players who experienced flow were more likely to share personal information and carry out word-of-mouth promotions. Also, several studies have found flow to be a contributing factor to addiction in gaming (Chou and Ting, 2003; Khang et al., 2013; Wu et al., 2013). In contrast, a study by Wan and Chiou (2006) indicated that flow and addictive tendencies are negatively correlated. Wan and Chiou's (2006) study shows that flow contributes to satisfaction for non-addicts whereas dissatisfaction avoidance is the reason people get addicted to games. Moreover, the research findings indicate that the flow state of non-addicts is greater than that of addicts. Hence, flow experiences may not be the key factor causing addiction.

\subsubsection{User-game experience}

Flow in gaming can produce user-game experience such as enjoyment and satisfaction, both of which are positive affects. Positive affect has been shown to be an outcome of flow (Chiang et al., 2011). 
Enjoyment is a feeling that can arise from the flow experience (Kiili, 2005b; Weibel et al., 2008). Weibel et al. (2008) found that playing against a human-controlled opponent led to greater levels of flow than playing against a computer-controlled opponent, which in turn led to greater enjoyment in gameplay.

Satisfaction in gaming has been defined as "the extent to which users believe the available game meets playing requirements" [Hsu, (2010), p.54]. Through a survey study, Hsu (2010) concluded that flow experience contributed to satisfaction in playing the game.

\subsubsection{User performance}

Flow has been found to produce two outcomes related to user performance. These two outcomes are:

1 game performance

2 learning effectiveness.

Admiraal et al. (2011) observed that the more teams experienced flow and the less they got distracted from issues such as technical problems, the more positive outcomes they gained in game performance. In addition, the study by Kiili (2005b) shows that flow can contribute to learning effectiveness in a game-based learning context.

\section{Game design elements for inducing flow}

Games have long been understood as designed systems. Conceptualising games as designed 'artefacts' enables systems thinking, which allows analysis and design principles to be applied to develop the interactive components of the game (Hunicke et al., 2004). Analysing and designing games as a system that consists of a set of elements is one of the approaches that can be taken when designing games. Breaking games down in the design process to elements, or 'atoms', makes the process more explicit and clear (Brathwaite and Schreiber, 2009). Deterding et al. (2011, p.11) explained that the main goal of using game design elements is to create a gameful experience, which is the experience of "playing structured by rules and competitive strife toward goals".

Sweetser and Wyeth (2005) proposed a set of elements based on the flow dimensions in gameplay. Also, Cowley et al. (2008) proposed a set of mapping between game design elements and flow dimensions. Drawing on the empirical literature covered in this review, we identified a set of game design elements that are key to inducing flow during gameplay. These elements are:

1 Storyline or plot line, which depicts the narrative of a game, defines the process that a player has to go through in order to advance to another level or complete a task (Dubbels, 2013; Pagulayan et al., 2003).

2 Interactivity (or intuitive game mechanics) is the ability of game components to seamlessly enable communication between players and the game (Kim et al., 2005). 
3 PBL (points, badges, and leaderboards), a term coined by Werbach and Hunter (2012), comprises a set of game elements that are most commonly used in various games as well as non-game systems (Nah et al., 2013; Zichermann and Cunningham, 2011).

4 Levels or milestones refer to short-term goals of a game that signify success of players (Nah et al., 2013; Zichermann and Cunningham, 2011).

5 Controller type, or interface devices, is another element to induce flow in gaming (Thin et al., 2011).

6 Social interaction (such as competition, cooperation, chatting, and online communities) can create new challenges and serve as a form of motivation and feedback for players (Chang, 2013; Sweetser and Wyeth, 2005).

The relationship between these game design elements and components of flow are shown in Table 3. Following, we explain the details of these mappings.

Table 3 Mapping game design elements to flow components

\begin{tabular}{lcccccc}
\hline & \multicolumn{5}{c}{ Game design element } \\
\cline { 2 - 7 } Flow component & Storyline & Interactivity & $P B L$ & Levels & $\begin{array}{c}\text { Controller } \\
\text { type }\end{array}$ & $\begin{array}{c}\text { Social } \\
\text { interaction }\end{array}$ \\
\hline $\begin{array}{l}\text { Balance of } \\
\text { challenge and skill }\end{array}$ & & $\mathrm{X}$ & $\mathrm{X}$ & $\mathrm{X}$ & $\mathrm{X}$ & $\mathrm{X}$ \\
$\begin{array}{l}\text { Clear goals } \\
\text { Immediate }\end{array}$ & $\mathrm{X}$ & & $\mathrm{X}$ & $\mathrm{X}$ & & \\
feedback & & $\mathrm{X}$ & $\mathrm{X}$ & & & $\mathrm{X}$ \\
Concentration & & $\mathrm{X}$ & & & & \\
Control & & $\mathrm{X}$ & & & $\mathrm{X}$ & \\
Enjoyment & $\mathrm{X}$ & & $\mathrm{X}$ & & $\mathrm{X}$ & $\mathrm{X}$ \\
Immersion & $\mathrm{X}$ & $\mathrm{X}$ & & & $\mathrm{X}$ & \\
\hline
\end{tabular}

\subsection{Storyline}

Storyline is one of the game elements for enabling flow in gameplay (Rollings and Adams, 2003) and it can enhance the flow components of clear goals, enjoyment, and immersion. Players who understand or relate to the storyline are able to gather more information cues and perceive greater empathy with game characters during gameplay. For example, in Admiraal et al.'s (2011) study, players who paid more attention to procedures and the technology of the game instead of the storyline had difficulties getting into flow. Storyline helps players to comprehend the high level goal of the game that provides meaning and importance to the game (Pagulayan et al., 2003). These high level goals in games increase "significance, tension, and motivation to succeed in the action sequences" [Pagulayan et al., (2003), p.8] and cause players to be more "emotionally involved" (p.8) in the games, thus increasing their enjoyment in gameplay. Moreover, 
having a story enables players to be 'a part of the story', which increases their empathy with game characters and their immersion into gameplay (Sweetser and Johnson, 2004). Overall, storyline is a significant game design element in creating flow.

Moreover, Inal and Cagiltay (2007) indicate that narratology, including story, is more important for girls than for boys. In their study, boys valued complexities and challenges in the game more than story. Inal and Cagiltay's (2007) results suggest that the effect of story on flow experiences for men and women could be different. Furthermore, the emphasis on storyline is dependent on the type of games. Simpler games that focus more on action, such as arcade games, tend to focus less on storyline than games of greater complexity, such as role-playing online games (Rollings and Adams, 2003).

\subsection{Interactivity (intuitive game mechanics)}

Hunicke et al. (2004) define game mechanics as "the various actions, behaviors and control mechanisms afforded to the player within a game context". Salen and Zimmerman (2006) state that gameplay occurs when there is a good combination of rule-bound, reactive, and emergent process of action sequences belonging to one or more players. Salen and Zimmerman (2006) named such rules as game mechanics, which heavily influence a player's experience and govern the exploration of the game's possibility. Clear mechanics strengthen the "player/game interaction relationship" [Cowley et al., (2008), p.4]. Mechanics also affect gameplay dynamics (i.e., the run-time behaviour of player/game interaction) and aesthetics (Hunicke et al., 2004). Interactivity, which brings across the mechanics in a game, is capable of helping to increase the flow experiences of game players through the following flow components: balance of challenge and skill, immediate feedback, concentration, control, and immersion.

In a gaming context, Admiraal et al. (2011) studied the effect of distractive activities, including navigation and technology (e.g., tools, interfaces, and connections) issues on student engagement in collaborative game-based learning. Based on their study, they found distractive activities to have a negative correlation with flow in the game-based learning environment. Admiraal et al.'s (2011) conclusion was that tools (such as video/text messaging and location information), if used in games, should not give wrong or misleading information as it could disrupt the player's flow experience. Such technological failures or distractions prevented subjects from moving on to the next level and hindered their engagement in gameplay. Hence, providing intuitive game mechanics to improve interactivity is important for maintaining the player's focus on the game, which can also help to enhance the player's sense of control and immersion in gameplay.

In addition, research by Kim et al. (2005) provides empirical support for the relationship between interactivity and the challenge and skill dimensions of flow. In other words, interactivity can enhance the challenge in the game as well as the skill of the player. When interactivity is high, players perceive immediate feedback and are able to concentrate better on the task they are performing. Also, players should feel more in control and immersed in the activity instead of being distracted by the use of technology. Previous research has shown a positive relationship between 'machine interactivity' and focused attention or concentration which is a component of flow (Kim et al., 2005). Kim et al.'s (2005) research further supported the relationship between interactivity and flow among video game players. 


\subsection{PBL (points, badges, and leaderboards)}

Points are key elements that have been used in games for years (Werbach and Hunter, 2012). Points have even been used in non-game contexts to create the notion of achievement (Zichermann and Cunningham, 2011). Other game design elements are often dependent on the game's point system. For example, to go to the next level in a game, players have to accumulate a certain amount of points. Various point systems (e.g., redeemable points, experience points, and karma points) can be deployed for various purposes, each having different effects on players' engagement in games (Zichermann and Cunningham, 2011).

Unlike points, badges have been derived from the physical or real world to indicate some sort of achievement in games (Zichermann and Cunningham, 2011). Leaderboards, on the other hand, rank players among other players, i.e., among all players or only one's friends, based on their score or achievement in a game. Both badges and leaderboards are generally based on points and they enable players to compare themselves with one another. The final goal of badges and leaderboards is to motivate players to play and be engaged in gameplay.

PBL can help to enhance the following flow components: balance of challenge and skill, clear goals, immediate feedback, and enjoyment. The lack of gamefulness is a reason for not experiencing flow, which can be overcome by deploying game elements such as PBL (Kiili, 2005b). PBL can be used to foster flow experiences of game players by challenging players. As players are challenged, they strive to improve their skills through acquiring PBL. For example, points challenge the players to improve their skills and advance in the game. Similarly, gaining badges can give a person a sense of competence through increasing perceptions of their skills. Badges also pose new challenges to players. Leaderboards can have a similar effect in challenging the players who value seeing their names at the top of a rank of players.

PBL also offers clear goals that the players need to achieve. Gaining a targeted amount of points, receiving a certain badge, or being at the top of a leaderboard can be a player's goal. These outcomes can also be a source of enjoyment for players due to the feeling of satisfaction that they distil in successful players. Through gaining PBL, players will receive immediate feedback on their performance, which further enhances their flow experience. For example, Sepehr and Head (2013) show that PBL, through creating competition among players, are very effective in engaging students in learning and creating flow experiences.

\subsection{Levels}

Another game design element that has been used to show the progress of players is levels or milestones (Zichermann and Cunningham, 2011). Levels can contribute to the following flow components: clear goals and balance of challenge and skill. Whereas storyline sets a high-level goal of a game, levels provide lower level and intermediate sets of goals. When a game is divided into multiple levels, the achievements are distributed more evenly across gameplay. More importantly, the steps to reach the goals in the game become more granular and achievable, which increase the clarity of the goals to the players, thus satisfying an important component of flow.

In addition to clear goals, properly designed levels can assist with achieving an appropriate balance of challenge and skill by properly adapting the challenge to current 
skill levels. In a well-designed game, players start with almost no skill in a specific game but, after completing each level, gain new skills which can be matched with greater challenges in the next levels. The feeling of achievement at the end of each level itself can uplift the players' sense of competence and, therefore, their perception of skills. Optimally, the challenge of these levels should be matched to the players' skill levels (Pagulayan et al., 2003).

\subsection{Controller type}

Controller types are especially important in video games, where multiple devices and technologies can be used for interacting with the game system (Bianchi-Berthouze et al., 2007). With the advancement of technology, many different forms of interactions have been invented for playing video games beyond traditional controllers such as mouse and keyboard. For example, with the pervasiveness of smartphones, various touchscreen-based controllers have been implemented. In addition, more technologically advanced controllers are now being used, such as motion sensing controllers in Nintendo's Wii Remote ${ }^{\circledR}$ and Microsoft's Kinect ${ }^{\circledR}$.

Controller types can affect the following flow components: balance of challenge and skills, control, enjoyment, and immersion. Controllers are the interaction medium between players and the game, and they affect the control component of flow in gameplay. Moreover, if improperly designed, controllers can pose greater challenges and require more skills. Thin et al. (2011) have demonstrated that body motion-based controllers resulted in higher balance in challenge and skill compared to physical exercise. Natapov et al. (2009) also compared interactions in a variety of tasks in a game using a motion sensing remote versus a non-motion sensing remote versus a mouse. Their results indicate that the error rate of each controller can be different for each task. Browne and Anand (2012) tested the effectiveness of three different types of controllers on mobile devices. The controller types in their comparisons are accelerometer-based interface, simulated buttons on touch screen, and touch screen-based controller with finger gestures. Their results indicate that the different controllers can have diverging effects on the player's effectiveness and enjoyment.

Lastly, the new body motion technologies have introduced more advanced methods of controlling games. With these controlling systems, one is able to have a more lifelike experience which can result in higher immersion (Thin et al., 2011). Bianchi-Berthouze et al. (2007) have also tested the effect of body movement controllers and identified their positive effect on the immersion of players.

\subsection{Social interaction}

Sweetser and Wyeth (2005) proposed social interaction as a game design element that facilitates flow. Social interaction, according to Sweetser and Wyeth (2005), includes competition and cooperation among players and establishing connections through any other forms of interactions such as chatting or sharing information in bulletin boards and social communities. Social interactions can enhance the following flow components: balance of challenge and skills, immediate feedback, and enjoyment. Kim et al. (2005) demonstrated that human interactivity has effects on one's perceptions of challenge and skills in gaming. Weibel et al. (2008) also demonstrated that playing against a human 
opponent resulted in more frequent flow experiences in comparison to playing against a non-human opponent. Through the various social interactions, specifically competitions, the level of challenge could be substantially increased to match the higher skill levels of advanced players, thus keeping them in the flow zone. Further, through social comparisons, e.g., with friends or other people, one can receive instant feedback regarding one's skills or performance. Interacting with others also increases the fun element of the game and one's enjoyment in gaming.

However, groups of people can differ in their preference for social interaction. For example, Inal and Cagiltay (2007) studied social interaction among children during gameplay. Their results indicate that boys tended to form groups more frequently and they experienced flow more frequently than girls.

\section{Conclusions and implications}

Our synthesis of the literature identified nine themes or streams of research in the context of flow and gaming. These include learning and education, presence, adoption, addiction, neural correlates of flow, measurement of flow, e-marketing, interactivity, and nomological network for flow. Implications of our findings for both research and practice are discussed below.

\subsection{Implications for research}

In the context of learning and education in gaming, our findings suggest that achieving beneficial learning outcomes is dependent upon attaining the right mix of flow components. For example, one research study found that team flow did not have a positive impact on learning outcomes, but did find a positive impact on learning when teams were comprised of individuals from higher educational levels (Admiraal et al., 2011). One explanation is that the game is more suited for those from higher educational levels. Hence, research will need to ensure that the game utilised presents challenges that match the skill sets of the participants to induce flow.

Introducing competition in game-based learning activities has also been shown to have a positive impact on learning outcomes (Admiraal et al., 2011; Beylefeld and Struwig, 2007; Sepehr and Head, 2013). Therefore, researchers may want to assess the integration of different competitive gaming formats in an educational context. Also, distractions, such as technology-related issues, will need to be minimised for positive learning outcomes to be achieved (Admiraal et al., 2011; Kiili, 2005b). Consideration should also be given to the age of the participants such that perceptions of ease of use for various age groups are factored into the design in order to facilitate flow (Hwang et al., 2011). For younger age groups, gender may impact flow experiences with ludology impacting boys and narratology impacting girls (Inal and Cagiltay, 2007).

In regards to team-based learning, research has demonstrated that teams that were cooperating more effectively experienced heightened levels of flow in comparison to those that were not (Raphael et al., 2012). Hence, research that focuses on or incorporates team-based activities will need to consider mechanisms or platforms that facilitate cooperative efforts among team members, and assess how group performance can be enhanced in such arrangements. 
Other factors to consider in research focusing on flow and gaming is presence and telepresence (Faiola et al., 2013; Jin, 2011, 2012). Variations of presence that have been found to induce flow include spatial presence (i.e., being transported to a virtual location), physical presence (i.e., perceiving virtual objects as real), and self-presence (i.e., identifying one's physical being with a virtual being). Researchers can consider various antecedents to presence that have been previously identified in studies, including using human-controlled opponents (versus computer-controlled), facilitating an emotional connection with the game or characters, and using game genres that match the interests of participants (Scoresby and Shelton, 2011; Weibel et al., 2008).

In regards to gaming adoption and flow research, our findings suggest flow to have a positive impact on user adoption. In this context, various antecedents to flow that have been identified included hedonic and utilitarian value, social and computer interactions, user satisfaction, mobile connection quality, content quality, and perceived ease of use (Chang, 2013; Hsu and Lu, 2004; Zhou, 2013). Other factors that can be considered in gaming and adoption studies that have been found to directly influence adoption include social factors (e.g., social norms) and user satisfaction (Hsu and Lu, 2004; Zhou 2013).

A potential outcome of flow in a gaming context is addiction. Research can consider factors that were identified in this review, such as repetitive behaviour, usage time, engagement as a pastime activity, specialisation in gaming, and self-control, and their effects on flow and addictive tendencies (or the relationship between them) (Chou and Ting, 2003; Khang et al., 2013). Other factors influencing addiction, but not necessarily flow, include self-presence and information seeking behaviours. One previous study found a negative relationship between addictive tendencies and flow, where addictions were viewed as a means to avoid feelings of dissatisfaction versus a means to acquire feelings of satisfaction (Wu et al., 2013), thus clearly differentiating flow from addictive tendencies conceptually.

In regards to measuring flow in a gaming context, our findings indicate that a six-component flow scale has been developed and validated (Fang et al., 2013). Also, the DFS-2 was tested in the gaming context using two different research studies with mixed results, where Wang et al. (2009) validated the instrument using elementary students versus Procci et al. (2012) invalidated the instrument using college students. Hence, research may need to consider the participants recruited for their studies and possibly reassess the validity of this instrument for studying flow in a gaming context.

In the domain of marketing, gaming and flow have received attention by researchers, but mixed results have also been reported. Factors such as achieving an optimal balance of skill and challenge are needed to induce flow, which can then influence propensity to share personal information and share information with others (Renard, 2013). Although research has found that more advanced players may be less likely to experience flow, those who achieved flow were unable to recognise or recall the brand. As Schneider and Cornwell (2005, p.336) noted, "it is conceivable that given our self-selected sample, the level used within the game was too easy for our experts and subsequently did not lead to flow". This may suggest that achieving a balance of skill and challenge is important for flow to occur in a marketing context, similar to education and learning contexts noted previously, which results in positive outcomes.

Also, to be considered with the balance of challenge and skill is the component of interactivity. Both human and machine interactivity have been found to impact flow 
through the balance of challenge and skill (Kim et al., 2005). Hence, research can integrate both interactivity and balance of challenge and skill to induce flow.

Studies have also assessed nomological networks of flow in a gaming context and found various factors that can be considered. For instance, non-violent games are more likely to induce flow (Chiang et al., 2011). Also, certain user characteristics can induce flow, including computer self-efficacy and one's competitive anxiety, and individuals with lower self-concept clarity spend more time playing games which induces flow (Hong et al., 2012; Lee et al., 2012). These studies also found support for perceived ease of use and balancing challenge and skill to be antecedents of flow, as noted earlier, as well as immediate feedback (Hsu, 2010; Voiskounsky et al., 2004). Hence, researchers will also want to consider these factors.

\subsection{Implications for practice}

For practitioners, a number of suggestions and implications can be derived from our synthesis of the literature.

Gaming has the potential to fulfil many needs for facilitating flow resulting in positive outcomes. For example, flow has influenced positive learning outcomes (Kiili, 2005a). Gaming can provide interactive, real-time, feedback intensive, rewarding, and collaborative experiences. An important aspect of gaming is inducing the flow experience, although not all components of flow may be needed (Chen, 2007). Flow may occur and be maintained by achieving optimal balances of challenge and requisite skill (Admiraal et al., 2011). Providing an experience in which low challenge is matched with low skill requirements, the player may lose interest or attention. However, if a mismatch occurs (i.e., low challenge and high skill, or high challenge and low skill), then the player may become bored or anxious, respectively.

Therefore, system design will need to incorporate flexibility in the levels of game challenge by matching them to the user's skills to facilitate flow, and offering help and assistance (e.g., scaffolding) whenever appropriate. Also, system designers will also want to consider progressive development of players' skills. As individuals develop or improve existing skill sets, they may fall into a state of boredom. Hence, introducing increasing levels of challenge to equate to increasing levels of skill, or developing an adaptive game, will be important for flow to be attained and maintained (Admiraal et al., 2011; Bressler and Bodzin, 2013; Chen, 2007; Kiili, 2005b).

Also, interactivity can impact flow through the balance of challenge and skill that is experienced. Two aspects that game designers can consider are human and computer interactivity. Gamers can assist each other with the game or gameplay, provide advice or knowledge about certain aspects of the game, or collaborate to achieve a certain objective. Therefore, designers will want to incorporate communication tools that are easy to use and are efficient. The game itself should be easy to use, with clear goals and immediate feedback. Also, designers can enhance the machine interactivity by providing help functions or quick references to improve gamers' chances of addressing a challenge or acquiring additional skills.

In the context of education and learning, games have the potential to foster learning if certain conditions and experiences, such as flow, are present. Designers or educators may consider utilising competitive games to improve flow. Team-based activities can also be included, but educators will want to ensure that they provide training to students regarding cooperative learning techniques. For educational games that are played on 
mobile devices, educators will also want to provide an environment that allows total concentration on the game and provides an intrinsically rewarding experience. Games that facilitate active learning can induce flow, but games that are not of interest to students are not likely to induce flow.

From a marketing perspective, gaming provides opportunities to engage existing and potential customers. Previous research has demonstrated the positive impact that $3 \mathrm{D}$ virtual worlds can have on brand equity, mediated by telepresence and enjoyment (Nah et al., 2011). Research has demonstrated that unintended consequences can also occur in which a participant may be so engaged in the richness of the mediated environment that they do not mindfully attend to the marketing messages being delivered. Hence, the environment itself can produce negative effects on brand equity. Therefore, designers and marketers will want to offer games that provide an appropriate balance of challenge and skills without distractions due to the rich environment, and provide individuals the opportunity to get accustomed to the game or virtual environment before introducing advertising messages.

Three different types of presence that have been found to facilitate flow can be considered in game design, including spatial, physical, and self-presence. To facilitate spatial presence, designers will want to develop an environment in which the participant feels like they have entered the virtual environment and can occupy or submerse themselves in the environment. For physical presence, designers may consider providing objects that are familiar to participants or objects that they can touch or manipulate such that the virtual object is perceived as part of reality. Designers may also consider focusing on self-presence, or participants' ability to identify their real self with a virtual character. Also, telepresence can be facilitated through quick response times, high interactivity, and vivid images.

Based on the review of the literature, system design will need to be optimised such that the game can facilitate flow and minimise problems or distractors in order to achieve the objectives of the task. Sporadic rewards or recognition of achievement to foster feelings of competence may also be introduced considering that feelings of competence have also been noted as influencing flow experiences. Designers can be less concerned about the viewing perspective that participants utilise (i.e., first- or third-person perspective), but can focus more on the game's engagement, relevant game content, intrinsic motivators, and participant's emotional connection to the game to generate flow. To facilitate flow, games can be designed to incorporate human-controlled (versus computer-controlled) opponents, thus enhancing the social interaction game element.

Flow can facilitate the successful adoption of a game. Designers will need to enhance the game's interactivity, including with other participants, and provide both hedonic and utilitarian value to participants. Evaluations and soliciting feedback from users will also be important to ensure users are satisfied with the gaming experience and perceive it as being easy to use, which are also contributors to flow.

The flow experience that can facilitate adoption can also result in negative outcomes such as addiction. Hence, practitioners need to be aware of certain signs to detect unhealthy gaming. For instance, addicts will game continuously, sometimes without taking breaks for sleeping or eating. Companies can monitor the amount of continuous playtime and send messages to the individuals to help remind them to take breaks, or institute mandatory breaks which, after a certain interval of time has passed, the player is rewarded for. Addicts tend to be more specialised players, such as joining specific 
gaming clubs. Information regarding signs and symptoms of gaming addiction, as well as treatment options, can be provided to these members. Also, researchers have suggested that addicts play games to avoid dissatisfaction rather than to obtain satisfaction (Wan and Chiou, 2006). Hence, addressing gaming addictions will need to encompass not only the problematic gaming behaviour, but also address the source of the dissatisfaction so the addiction does not reoccur or manifest into an alternative addiction.

\title{
6.3 Future research
}

A variety of antecedents and outcomes of flow were validated in the empirical papers reviewed. These antecedents and outcomes were discussed, and a general framework for flow in online gaming is proposed. The factors identified from our review can be used to develop a nomological network for understanding flow in the gaming context and to extend flow theory to the gaming context.

Future research can also assess whether it is possible to establish a standardised measurement for flow in all contexts or if different sets of flow measurement need to be developed for different contexts, such as the case of physical versus cognitive activities. Quoting Voiskounsky et al. (2004) who cited Rettie (2001, pp.111, 265),

\begin{abstract}
"... we are inclined to expect that there possibly are numerous sets of flow dimensions, or let us informally call them 'flow dialects', which are strongly dependent on task specificity, and probably on some other parameters. Flow patterns inherent of ICT related behaviors, too, differ a lot: flow experienced while online shopping might be described using a set of dimensions which only partly match the dimensions describing flow experienced while online gaming, or navigating the web, etc. Rettie (2001) states that 'while respondents recognized most of Csikszentmihalyi's dimensions, the merging of action and awareness and loss of self-consciousness were not really relevant..."
\end{abstract}

Also, future research can further explore the relationship of flow with the various components considering research has modelled the components in a variety of functional roles. For instance, the balance of challenge and skill, time distortion, and focused attention have been modelled as antecedents as well as dimensions of flow. Therefore, research can assess and compare competing models of flow, and assess potential mediators and moderators of the components of flow. Additional factors that could be influential to flow experiences can also be explored. Previous research has identified user characteristics, such as computer self-efficacy, to influence flow in a gaming context, but additional user characteristics could be explored. For instance, future research could evaluate attributes such as personal innovativeness in the domain of information technology (Agarwal and Prasad, 1998) or mindfulness (Butler and Gray, 2006).

Our literature review identified nine major themes or research streams of flow in the context of gaming. Education and learning has had the largest focus in the literature thus far, while neural correlates of flow and e-marketing have had the least amount. Therefore, research can continue advancing any of the themes that we have identified. Alternatively, future research can explore additional themes or develop additional streams of research in flow and gaming. For example, the balance of challenge and skill was noted as a relevant component of flow in several research articles (e.g., Jin, 2011, 2012). Future research may focus on this component more extensively such as identifying the ideal balance between challenge and skill. For instance, research could assess the impact on flow when challenge and skill are perfectly equivalent, challenge is slightly emphasised more than 
skill such that the participant is motivated to achieve the next level, or skill is slightly emphasised more than challenge such that the participant feels competent and stays engaged. This investigation could be examined separately for experienced versus novice players, and with different types of players (e.g., students versus consumers).

In order to have the essential flow components present in an educational gaming context, a game should not only ensure optimal balance of challenge and skill, but also have established goals and offer immediate feedback (Kiili, 2005b). Games in education should provide positive, enjoyable, and engaging activities such that the flow experience can be realised. Hence, suggestions have been made that IT artefacts be designed such that attention is focused on the activity and not on using the technology. Also, consideration needs to be given to the storyline or plot of the game such that participants understand the background for the game, attend to and comprehend the educational content, or are able to apply the concepts learned. Also, recommendations have been put forth that participants of lower-level abilities do not feel overwhelmed or hopeless and the game encourages their continued use and engagement. Hence, future research can explore the optimal design of IT artefacts, such as the format that the content are delivered. In this regard, researchers can further explore using a computer, hand-held, or body-controlled device. Future research can explore the adaptability of the games for individuals of low-level abilities that provide support so gameplay is not abandoned, yet provides enough challenge to induce flow.

Future research can also explore the impact of interest in the topic or plot of the game, versus interest in technology or gaming, and the impact on flow. Previous research has identified that interest in the topic of an educational game did not predict flow, but attitude towards playing games did (Bressler and Bodzin, 2013). Interestingly, after gameplay occurred, participants generated an interest in the topic. Hence, future research can also explore the influence flow can have on generating subject interest, especially for subjects that participants typically dislike or find less appealing. This could be conducted in education and learning contexts, or marketing and brand awareness in which interest in a new product or service could be generated.

Previous research has identified the flow experience being realised by teams who engaged in cooperative learning, with each team consisting of two players. Considering that some activities are more conducive to larger team sizes, future research may explore the size of teams and the ability to engage in the flow experience beyond two-member teams. Also, further studies are required to identify the effect of the social interaction elements on flow components and the moderating effect of gender and other personality factors on this relationship.

Although online gaming can facilitate flow and, thus, produce an enjoyable and engaging experience, negative outcomes, such as addictions, can also occur. These behaviours can result in socialisation, sleep, career or academic performance, and health issues (Beranuy et al., 2013). The impetus for these addictions has been attributed to needs for entertainment, feelings of commitment to other players, and opportunities to avoid real-life conflicts or issues. Addicts can become depressed or feel guilty if they don't play, become pre-occupied with thoughts of playing, and experience loss of control. Future research can explore possibilities of system design that can potentially prevent or deter addictions.

For example, research can explore the potential of rewarding individuals, or their teams, for taking a break or a leave of absence after a given number of hours of 
continuous play. If individuals indicate that they feel they need to play because others are dependent on them and they lose their sense of time, the game would assist in monitoring play time and offer incentives to stop playing because they would feel obligated to earn the rewards for the benefit of their team. As has been previously noted, "people in flow temporarily tolerate a lack of stimulation if they believe stimulation will resume shortly" [Bressler and Bodzin, (2013), p.514]. Research can evaluate the ability to re-engage in the flow experience after a given amount of rest or time, the amount of time to re-engage, the optimal amount of absence (i.e., preventing addiction while still continuing healthy levels of gaming), and models for predicting intentions to use in the future. Hence, researchers can focus on developing loyalty but not induce addiction (Chou and Ting, 2003). Considering research using EEG and fMRIs have been able to detect flow occurrences, future research may be able to employ these technologies to study flow occurrences in addicts versus non-addicts.

\subsection{Conclusions}

Our synthesis of the flow and gaming literature suggests nine salient research themes: gaming in learning and education, presence, adoption, addiction, neural correlates of flow, measurement of flow, e-marketing, interactivity, and nomological network for flow. Although current research has made notable contributions, future research can extend these existing streams, as well as extend these research streams in new directions. We have also identified antecedents, dimensions, and outcomes of flow in the gaming literature and derived a framework that can be used in future research. From our review, we provided suggestions for both research and practice, and have proposed topics for future research. More specifically, our research contributes to these efforts by providing a starting point for research to commence, ideas for additional contributions to existing and new research streams, and a framework to apply or guide researchers. For practice, we provide suggestions for systems designers and relevant stakeholders. Flow and gaming research is still in its infancy, although it has made a prominent impact in education, recreation, and business endeavours. Hence, continuation of research in flow and gaming is warranted and the synthesis of the literature we conducted can assist in these efforts.

\section{Acknowledgements}

We would like to thank Rushika Singh at the Missouri University of Science and Technology for her help and involvement in the earlier part of this research project.

\section{References}

Admiraal, W., Huizenga, J., Akkerman, S. and ten Dam, G. (2011) 'The concept of flow in collaborative game-based learning', Computers in Human Behavior, Vol. 27, No. 3, pp.1185-1194.

Agarwal, R. and Prasad, J. (1998) 'A conceptual and operational definition of personal innovativeness in the domain of information technology', Information Systems Research, Vol. 9, No. 2, pp.204-215.

Bandura, A. (1977) 'Self-efficacy: toward a unifying theory of behavioral change', Psychological Review, Vol. 84, No. 2, pp.191-215. 
Bandura, A. (1986) Social Foundations of Thought and Action: A Social Cognitive Theory, Prentice Hall, Englewood Cliffs, New Jersey.

Beranuy, M., Carbonell, X. and Griffiths, M.S. (2013) 'A qualitative analysis of online gaming addicts in treatment', International Journal of Mental Health and Addiction, Vol. 11, No. 2, pp.149-161.

Berta, R., Bellotti, F., De Gloria, A., Pranantha, D. and Schatten, C. (2013) 'Electroencephalogram and physiological signal analysis for assessing flow in games', IEEE Transactions on Computational Intelligence and AI in Games, Vol. 5, No. 2, pp.164-175.

Beylefeld, A.A. and Struwig, M.C. (2007) 'A gaming approach to learning medical microbiology: students' experiences of flow', Medical Teacher, Vol. 29, Nos. 9-10, pp.933-940.

Bianchi-Berthouze, N., Kim, W.W. and Patel, D. (2007) 'Does body movement engage you more in digital game play? And why?', in Luo, J. (Ed.): Affective Computing and Intelligent Interaction, pp.102-113, Springer, Berlin Heidelberg.

Biocca, F. and Delaney, B. (1995) 'Immersive virtual reality technology', in Biocca, F. and Levy, M.R. (Eds.): Communication in the Age of Virtual Reality, pp.57-124, Lawrence Erlbaum Associates, Hillsdale, New Jersey.

Brathwaite, B. and Schreiber, I. (2009) Challenges for Game Designers, Course Technology/Cengage Learning, Boston, Massachusetts.

Bressler, D.M. and Bodzin, A.M. (2013) 'A mixed methods assessment of students' flow experiences during a mobile augmented reality science game', Journal of Computer Assisted Learning, Vol. 29, No. 6, pp.505-517.

Browne, K. and Anand, C. (2012) 'An empirical evaluation of user interfaces for a mobile video game', Entertainment Computing, Vol. 3, No. 1, pp.1-10.

Butler, B.S. and Gray, P.H. (2006) 'Reliability, mindfulness, and information systems', MIS Quarterly, Vol. 30, No. 2, pp.211-224.

Chang, C-C. (2013) 'Examining users' intention to continue using social network games: a flow experience perspective', Telematics and Informatics, Vol. 30, No. 4, pp.311-321.

Charlton, J. and Danforth, I. (2007) 'Distinguishing addiction and high engagement in the context of online game playing', Computers in Human Behavior, Vol. 23, No. 3, pp.1531-1548.

Chen, J. (2007) 'Flow in games (and everything else)', Communications of the ACM, Vol. 50, No. 4, pp.31-34.

Chiang, Y., Lin, S.S.J., Cheng, C. and Liu, E.Z. (2011) 'Exploring online game players' flow experiences and positive affect', Turkish Online Journal of Educational Technology, Vol. 10, No. 1, pp.106-114.

Choi, D., Kim, J. and Kim, S. (2007) 'ERP training with a web-based electronic learning system: the flow theory perspective', International Journal of Human-Computer Studies, Vol. 65, No. 3, pp.223-243.

Chou, T. and Ting, C. (2003) 'The role of flow experience in cyber-game addiction', Cyberpsychology \& Behavior, Vol. 6, No. 6, pp.663-675.

Cowley, B., Charles, D., Black, M. and Hickey, R. (2008) 'Toward an understanding of flow in video games', ACM Computers in Entertainment, Vol. 6, No. 2, Article 20, pp.1-27.

Csikszentmihalyi, M. (1990) Flow: The Psychology of Optimal Experience, Harper \& Row, New York, New York.

Csikszentmihalyi, M. (1997) Finding Flow: The Psychology of Engagement with Everyday Life, Basic Books, New York, New York.

Davis, F. (1989) 'Perceived usefulness, perceived ease of use, and user acceptance of information technology', MIS Quarterly, Vol. 13, No. 3, pp.319-339.

Deci, E.L. and Ryan, R.M. (1985) 'The general causality orientations scale: self-determination in personality,' Journal of Research in Personality, Vol. 19, No. 2, pp.109-134. 
Deterding, S., Dixon, D., Khaled, R. and Nacke, L. (2011) 'From game design elements to gamefulness: defining 'gamification', in Proceedings of the 15th International Academic MindTrek Conference: Envisioning Future Media Environments, pp.9-15.

Dubbels, B. (2013) 'Gamification, serious games, ludic simulation, and other contentious categories', International Journal of Gaming and Computer-Mediated Simulations, Vol. 5, No. 2, pp.1-19.

Faiola, A., Newlon, C., Pfaff, M. and Smyslova, O. (2013) 'Correlating the effects of flow and telepresence in virtual worlds: enhancing our understanding of user behavior in game-based learning', Computers in Human Behavior, Vol. 29, No. 3, pp.1113-1121.

Fang, X., Zhang, J. and Chan, S.S. (2013) 'Development of an instrument for studying flow in computer game play', International Journal of Human-Computer Interaction, Vol. 29, No. 7, pp.456-470.

Hartmann, T. and Klimmt, C. (2006) 'Gender and computer games: exploring females' dislikes', Journal of Computer-Mediated Communication, Vol. 11, No. 4, pp.910-931.

Hong, J., Chiu, P., Shih, H. and Lin, P. (2012) 'Computer self-efficacy, competitive anxiety and flow state: escaping from firing online game', The Turkish Online Journal of Educational Technology, Vol., 11, No. 3, pp.70-76.

Hong, J., Hwang, M., Chen, W., Lee, C., Lin, P. and Chen, Y. (2013) 'Comparing the retention and flow experience in playing solitary and heart attack games of San Zi Jing: a perspective of dual process theory', Computers and Education, November, Vol. 69, pp.369-376.

Hsu, C. (2010) 'Exploring the player flow experience in e-game playing', International Journal of Technology and Human Interaction, Vol. 6, No. 2, pp.47-64.

Hsu, C. and Lu, H. (2004) 'Why do people play on-line games? An extended TAM with social influences and flow experience', Information \& Management, Vol. 41, No. 7, pp.853-868.

Hunicke, R., LeBlanc, M. and Zubek, R. (2004) 'MDA: a formal approach to game design and game research', in Proceedings of the Workshop on Challenges in Game AI, 19th National Conference on Artificial Intelligence, AAAI Press, San Jose, California.

Hwang, M., Hong, J., Hao, Y. and Jong, J. (2011) 'Elders' usability, dependability, and flow experiences on embodied interactive video games', Educational Gerontology, Vol. 37, No. 8, pp.715-731.

Inal, Y. and Cagiltay, K. (2007) 'Flow experiences of children in an interactive social game environment', British Journal of Educational Technology, Vol. 38, No. 3, pp.455-464.

Jackson, S.A. and Eklund, R.C. (2002) 'Assessing flow in physical activity: the flow state scale-2 and dispositional flow scale-2', Journal of Sport and Exercise Psychology, Vol. 24, No. 2, pp.133-150.

Jegers, K. (2007) 'Pervasive game flow: understanding player enjoyment in pervasive gaming', ACM Computers in Entertainment, Vol. 5, No. 1, Article 9, pp.1-11.

Jin, S. (2011) 'I feel present. Therefore, I experience flow: a structural equation modeling approach to flow and presence in video games', Journal of Broadcasting \& Electronic Media, Vol. 55, No. 1, pp.114-136.

Jin, S. (2012) 'Toward integrative models of flow: effects of performance, skill, challenge, playfulness, and presence on flow in video games', Journal of Broadcasting \& Electronic Media, Vol. 56, No. 2, pp.169-186.

Khang, H., Kim, J.K. and Kim, Y. (2013) 'Self-traits and motivations as antecedents of digital media flow and addiction: the internet, mobile phones, and video games', Computers in Human Behavior, Vol. 29, No. 6, pp.2416-2424.

Kiili, K. (2005a) 'Digital game-based learning: toward an experiential gaming model', Internet and Higher Education, Vol. 8, No. 1, pp.13-24.

Kiili, K. (2005b) 'Content creation challenges and flow experience in educational games: the IT-emperor case', Internet and Higher Education, Vol. 8, No. 3, pp.183-198. 
Kim, Y., Oh, S. and Lee, H. (2005) 'What makes people experience flow? Social characteristics of online games', International Journal of Advanced Media and Communication, Vol. 1, No. 1, pp.76-91.

Klasen, M., Weber, R., Kircher, T.J., Mathiak, K.A. and Mathiak, K. (2012) 'Neural contributions to flow experience during video game playing', Social Cognitive and Affective Neuroscience, Vol. 7, No. 4, pp.485-495.

Lee, C., Aiken, K. and Hung, H. (2012) 'Effects of college student's video gaming behavior on self-concept clarity and flow', Social Behavior and Personality, Vol. 40, No. 4, pp.673-680.

Lombard, M. and Ditton, T. (1997) 'At the heart of it all: the concept of presence', Journal of Computer Mediated Communication, Vol. 3, No. 2.

Moore, G. and Benbasat, I. (1991) 'Development of an instrument to measure the perceptions of adopting an information technology innovation', Information Systems Research, Vol. 2, No. 3, pp.192-222.

Nah, F., Eschenbrenner, B. and DeWester, D. (2011) 'Enhancing brand equity through flow and telepresence: a comparison of 2D and 3D virtual worlds', MIS Quarterly, Vol. 35, No. 3, pp.731-747.

Nah, F., Telaprolu, V., Rallapalli, S. and Venkata, P. (2013) 'Gamification of education using computer games', in Yamamoto, S. (Ed.): Lecture Notes in Computer Science, Vol. 8018, pp.99-107, Springer-Verlag, Berlin Heidelberg.

Natapov, D., Castellucci, S.J. and MacKenzie, I.S. (2009) 'ISO 9241-9 evaluation of video game controllers', in Proceedings of Graphics Interface, Canadian Information Processing Society, pp.223-230.

Novak, T.P., Hoffman, D.L. and Yung, Y.F. (2000) 'Measuring the customer experience in online environments: a structural modeling approach', Marketing Science, Vol. 19, No. 1, pp.22-42.

Pagulayan, R.J., Keeker, K., Wixon, D., Romero, R.L. and Fuller, T. (2003) 'User-centered design in games', in Jacko, J. and Sears, A. (Eds.): Handbook for Human Computer Interaction in Interactive Systems, pp.883-906, Lawrence Erlbaum Associates, Inc., Mahwah, New Jersey.

Procci, K., Singer, A.R., Levy, K.R. and Bowers, C. (2012) 'Measuring the flow experience of gamers: an evaluation of the DFS-2', Computers in Human Behavior, Vol. 28, No. 6, pp.2306-2312.

Raphael, C., Bachen, C.M. and Hernández-Ramos, P.F. (2012) 'Flow and cooperative learning in civic game play', New Media and Society, Vol. 14, No. 8, pp.1321-1338.

Read, J.L. and Shortell, S.M. (2011) 'Interactive games to promote behavior change in prevention and treatment', Journal of the American Medical Association, Vol. 305, No. 16, pp.1704-1705.

Renard, D. (2013) 'Online promotional games: impact of flow experience on word-of-mouth and personal information sharing', International Business Research, Vol. 6, No. 9, pp.93-100.

Rettie, R. (2001) 'An exploration of flow during internet use', Internet Research, Vol. 11, No. 2, pp.103-113.

Rollings, A. and Adams, E. (2003) Andrew Rollings and Ernest Adams on Game Design, New Riders, Berkeley, California.

Salen, K. and Zimmerman, E. (Eds.) (2006) The Game Design Reader: A Rules of Play Anthology, MIT Press, Cambridge, Massachusetts.

Schneider, L. and Cornwell, T.B. (2005) 'Cashing in on crashes via brand placement in computer games: the effects of experience and flow on memory', International Journal of Advertising, Vol. 24, No. 3, pp.321-343.

Scoresby, J. and Shelton, B.E. (2011) 'Visual perspectives within educational computer games: effects on presence and flow within virtual immersive learning environments', Instructional Science, Vol. 39, No. 3, pp.227-254. 
Sepehr, S. and Head, M. (2013) 'Competition as an element of gamification for learning: an exploratory longitudinal investigation', in Proceedings of Gamification, Stratford, Ontario, Canada, pp.2-8.

Steuer, J. (1992) 'Defining virtual reality: dimensions determining telepresence', Journal of Communication, Vol. 42, Vol. 4, pp.72-92.

Sweetser, P. and Johnson, D. (2004) 'Player-centred game environments: assessing player opinions, experiences and issues', in Rauterberg, M. (Ed.): Entertainment Computing - ICEC 2004: Third International Conference, Lecture Notes in Computer Science, Springer Verlag, New York, New York, Vol. 3166, pp.321-332.

Sweetser, P. and Wyeth, P. (2005) 'GameFlow: a model for evaluating player enjoyment in games', ACM Computers in Entertainment, Vol. 3, No. 3, Article 3A, pp.1-24.

Thin, A.G., Hansen, L. and McEachen, D. (2011) 'Flow experience and mood states while playing body movement-controlled video games', Games and Culture: A Journal of Interactive Media, Vol. 6, No. 5, pp.414-428.

Trevino, L.K. and Webster, J. (1992) 'Flow in computer-mediated communication: electronic mail and voice mail evaluation and impacts', Communication Research, Vol. 19, No. 5, pp.539-573.

Voiskounsky, A.E., Mitina, O.V. and Avetisova, A.A. (2004) 'Playing online games: flow experience,' PsychNology Journal, Vol. 2, No. 3, pp.259-281.

Wan, C. and Chiou, W. (2006) 'Psychological motives and online games addiction: a test of flow theory and humanistic needs theory for Taiwanese adolescents', Cyberpsychology \& Behavior, Vol. 9, No. 3, pp.317-324.

Wang, C., Liu, W.C. and Khoo, A.A. (2009) 'The psychometric properties of dispositional flow scale-2 in internet gaming', Current Psychology: A Journal for Diverse Perspectives on Diverse Psychological Issues, Vol. 28, No. 3, pp.194-201.

Wang, L. and Chen, M. (2010) 'The effects of game strategy and preference-matching on flow experience and programming performance in game-based learning', Innovations in Education and Teaching International, Vol. 47, No. 1, pp.39-52.

Webster, J. and Martocchio, J.J. (1992) 'Microcomputer playfulness: development of a measure with workplace implications', MIS Quarterly, Vol. 16, No. 2, pp.201-226.

Weibel, D., Wissmath, B., Habegger, S., Steiner, Y. and Groner, R. (2008) 'Playing online games against computer- vs. human-controlled opponents: effects on presence, flow, and enjoyment', Computers in Human Behavior, Vol. 24, No. 5, pp.2274-2291.

Werbach, K. and Hunter, D. (2012) For the Win: How Game Thinking Can Revolutionize Your Business, Wharton Digital Press, Philadelphia, Pennsylvania.

Williams, D., Yee, N. and Caplan, S.E. (2008) 'Who plays, how much, and why? Debunking the stereotypical gamer profile', Journal of Computer-Mediated Communication, Vol. 13, No. 4, pp.993-1018.

Wu, T., Scott, D. and Yang, C. (2013) 'Advanced or addicted? Exploring the relationship of recreation specialization to flow experiences and online game addiction', Leisure Sciences, Vol. 35, No. 3, pp.203-217.

Zhou, T. (2013) 'Understanding the effect of flow on user adoption of mobile games', Personal and Ubiquitous Computing, Vol. 17, No. 4, pp.741-748.

Zichermann, G. and Cunningham, C. (2011) Gamification by Design: Implementing Game Mechanics in Web and Mobile Apps, O’Reilly Media, Inc., Sebastopol, California. 